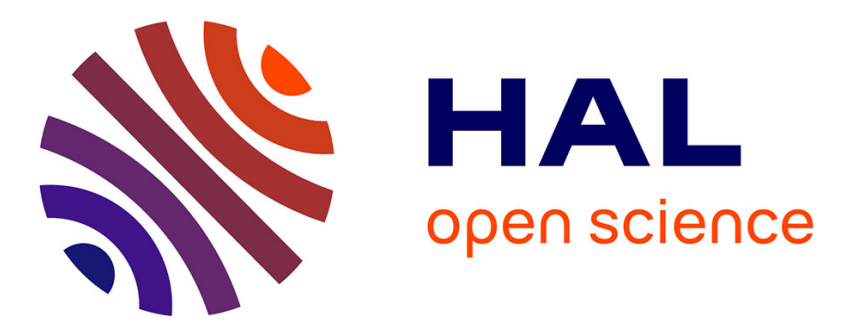

\title{
A first-of-its-kind multi-model convection permitting ensemble for investigating convective phenomena over Europe and the Mediterranean
}

Erika Coppola, Stefan Sobolowski, E. Pichelli, F. Raffaele, B. Ahrens, I. Anders, N. Ban, Sophie Bastin, M. Belda, D. Belusic, et al.

\section{To cite this version:}

Erika Coppola, Stefan Sobolowski, E. Pichelli, F. Raffaele, B. Ahrens, et al.. A first-of-its-kind multimodel convection permitting ensemble for investigating convective phenomena over Europe and the Mediterranean. Climate Dynamics, 2020, 55, pp.3-34. 10.1007/s00382-018-4521-8 . insu-01923722

\section{HAL Id: insu-01923722 \\ https://hal-insu.archives-ouvertes.fr/insu-01923722}

Submitted on 4 Jan 2021

HAL is a multi-disciplinary open access archive for the deposit and dissemination of scientific research documents, whether they are published or not. The documents may come from teaching and research institutions in France or abroad, or from public or private research centers.
L'archive ouverte pluridisciplinaire HAL, est destinée au dépôt et à la diffusion de documents scientifiques de niveau recherche, publiés ou non, émanant des établissements d'enseignement et de recherche français ou étrangers, des laboratoires publics ou privés. 


\title{
A first-of-its-kind multi-model convection permitting ensemble for investigating convective phenomena over Europe and the Mediterranean
}

\author{
Erika Coppola ${ }^{1}$ - Stefan Sobolowski ${ }^{2} \cdot$ E. Pichelli ${ }^{1} \cdot$ F. Raffaele ${ }^{1} \cdot$ B. Ahrens ${ }^{3} \cdot$ I. Anders ${ }^{4} \cdot$ N. Ban $^{5} \cdot$ S. Bastin ${ }^{6}$. \\ M. Belda ${ }^{7}$. D. Belusic ${ }^{8} \cdot$ A. Caldas-Alvarez ${ }^{9}$ R. M. Cardoso ${ }^{10} \cdot$ S. Davolio ${ }^{11} \cdot$ A. Dobler ${ }^{12} \cdot$ J. Fernandez $^{13} \cdot$ L. Fita $^{14}$. \\ Q. Fumiere ${ }^{15} \cdot$ F. Giorgi ${ }^{1} \cdot$ K. Goergen ${ }^{16,17} \cdot$ I. Güttler ${ }^{18} \cdot$ T. Halenka $^{7} \cdot$ D. Heinzeller ${ }^{19,20} \cdot \emptyset$. Hodnebrog ${ }^{21} \cdot$ D. Jacob $^{22}$. \\ S. Kartsios ${ }^{23}$ - E. Katragkou ${ }^{23}$ - E. Kendon ${ }^{24}$ - S. Khodayar ${ }^{9}$ H. Kunstmann ${ }^{19,25} \cdot$ S. Knist ${ }^{17,26}$ - A. Lavín-Gullón ${ }^{27}$. \\ P. Lind ${ }^{8} \cdot$ T. Lorenz ${ }^{2} \cdot$ D. Maraun ${ }^{28} \cdot$ L. Marelle ${ }^{21} \cdot$ E. van Meijgaard ${ }^{29}$. J. Milovac ${ }^{30} \cdot$ G. Myhre $^{21} \cdot$ H.-J. Panitz ${ }^{9}$.

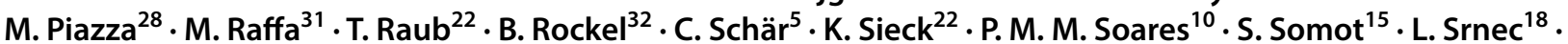

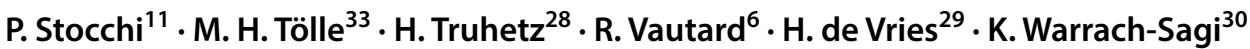

Received: 6 December 2017 / Accepted: 29 October 2018

(c) Springer-Verlag GmbH Germany, part of Springer Nature 2018

\begin{abstract}
A recently launched project under the auspices of the World Climate Research Program's (WCRP) Coordinated Regional Downscaling Experiments Flagship Pilot Studies program (CORDEX-FPS) is presented. This initiative aims to build first-ofits-kind ensemble climate experiments of convection permitting models to investigate present and future convective processes and related extremes over Europe and the Mediterranean. In this manuscript the rationale, scientific aims and approaches are presented along with some preliminary results from the testing phase of the project. Three test cases were selected in order to obtain a first look at the ensemble performance. The test cases covered a summertime extreme precipitation event over Austria, a fall Foehn event over the Swiss Alps and an intensively documented fall event along the Mediterranean coast. The test cases were run in both "weather-like" (WL, initialized just before the event in question) and "climate" (CM, initialized 1 month before the event) modes. Ensembles of 18-21 members, representing six different modeling systems with different physics and modelling chain options, was generated for the test cases (27 modeling teams have committed to perform the longer climate simulations). Results indicate that, when run in WL mode, the ensemble captures all three events quite well with ensemble correlation skill scores of $0.67,0.82$ and 0.91 . They suggest that the more the event is driven by large-scale conditions, the closer the agreement between the ensemble members. Even in climate mode the large-scale driven events over the Swiss Alps and the Mediterranean coasts are still captured (ensemble correlation skill scores of 0.90 and 0.62 , respectively), but the inter-model spread increases as expected. In the case over Mediterranean the effects of local-scale interactions between flow and orography and land-ocean contrasts are readily apparent. However, there is a much larger, though not surprising, increase in the spread for the Austrian event, which was weakly forced by the large-scale flow. Though the ensemble correlation skill score is still quite high (0.80). The preliminary results illustrate both the promise and the challenges that convection permitting modeling faces and make a strong argument for an ensemble-based approach to investigating high impact convective processes.
\end{abstract}

Keywords Convection-permitting $\cdot$ Ensemble models $\cdot$ Climate applications

This paper is a contribution to the special issue on Advances in Convection-Permitting Climate Modeling, consisting of papers that focus on the evaluation, climate change assessment, and feedback processes in kilometer-scale simulations and observations. The special issue is coordinated by Christopher L. Castro, Justin R. Minder, and Andreas F. Prein.

Extended author information available on the last page of the article

\section{Introduction}

Recent years have witnessed an explosive increase in climate simulations being run at convection permitting scales [so-called convection permitting regional climate modelling (CP-RCM)]. The types of models used in these experiments are generally, though not exclusively, limited area models 
with grid spacings under $4 \mathrm{~km}$ (Prein et al. 2015). Convection, and its related impacts, is of high interest to atmospheric scientists, climate impacts researchers and the public due to the role it plays in driving damaging extreme events such as heavy precipitation, floods, landslides, windstorms (Carvalho et al. 2002; Jakob and Weatherly 2003; Beniston 2006; Ducrocq et al. 2014; Stucki et al. 2015). It is also the dominant type of precipitation in many parts of the world, such as the tropics, and influences the general circulation of the atmosphere through tropospheric mixing and cloud - circulation interactions (e.g., Bony et al. 2015). Unfortunately, parameterization of convection, which is required at the grid spacing of most Global Climate Models (GCMs) and Regional Climate Models (RCMs), contributes to errors in climate simulations (Dirmeyer et al. 2012; Klein et al. 2013). Poor representation of convection and related processes also likely contributes to the uncertain response of the atmospheric circulation to changing greenhouse gas concentrations (Shepherd 2014; Sherwood et al. 2014; Webb et al. 2015). In addition to errors related to convection, along with clouds and circulations associated with it, many other physical parameterization schemes interact with models' convection schemes, raising the potential for consequences in other aspects of a climate simulation (Stevens and Bony 2013). These twin desires, the reduction of model errors associated with parameterized convection and a more detailed representation of present and future regional climate, have strongly motivated the recent increase in modeling activities at convection permitting scales.

There is a rich history in the Numerical Weather Prediction (NWP) and mesoscale meteorology communities of using convection permitting simulations for process and case studies (e.g., Benoit et al. 2002; Milovac et al. 2016; Schwitalla et al. 2017). These researchers have decades of experience running simulations at these resolutions and have shown the added value of resolving convective scale phenomena such as complex interactions with orography (e.g., Grell et al. 2000; Pontoppidan et al. 2017), precipitation intensity (e.g., Ducrocq et al. 2002, 2008; Davis et al. 2006) and severe weather (e.g., Weisman et al. 1997; Mass et al. 2002; Done et al. 2004; Khodayar et al. 2016). Although, it should be noted that some authors advocate for a severe change of data assimilation approaches, physics (e.g., microphysics), parameterizations and numerical methods to be used at convection resolving scales (Yano et al. 2015, 2017). Until recently there has not been as much attention to longer and scenario-based experiments (Kendon et al. 2012; Fosser et al. 2014; Prein et al. 2015). Further, climate change detection and attribution studies at convection permitting scales have only just begun. This has been due mainly to computational limitations and costs. With recent advances in processing speed and efficiency, research teams with an eye towards improving our understanding of processes driving societally relevant climate impacts, have begun developing and running $\mathrm{CP}-\mathrm{RCMs}$ at climate time scales.

A number of decade-long simulations have been completed in recent years with impressive results (Kendon et al. 2012; Warrach-Sagi et al. 2013; Fosser et al. 2014; Ban et al. 2014; Brisson et al. 2016; Déqué et al. 2016; Tölle et al. 2017). The benefits of running climate simulations ( $\sim 10$ years or more) at convection permitting grid spacings are far reaching. Among the improvements, compared to coarser resolution simulations, are a more accurate representation of diurnal cycles, hourly precipitation intensities, local-regional circulations, seasonal average precipitation, convective downdrafts, and the representation of cold pools (Prein et al. 2013a; Ban et al. 2014; Fosser et al. 2014; Kendon et al. 2012, 2014; Rasmussen et al. 2014; Brisson et al. 2016; Déqué et al. 2016; Fumière et al., this issue). In addition to the direct effects of resolving convective processes, - there are additional benefits through e.g., more accurate representation of interactions with complex topography, urban effects, land-ocean contrasts and land surface heterogeneities, which play a key role in forcing or triggering convection (Prein et al. 2013b). Convection-permitting climate simulations also allow the study of complex and fine scale aerosol-cloud-precipitation interactions as shown in Heinzeller et al. (2016). Finally, there are indications that CP-RCM simulations have positive indirect effects on the representation of regional climate through various feedback mechanisms such as soil moisture-precipitation (Hohenegger et al. 2009) and soil moisture/vegetation-temperature (Tölle et al. 2014) and urban effects (Argüeso et al. 2014). For example, there is indication for reduced mid-Europe summer warming (in its mean and extremes) in CP-RCM simulations (Tölle et al. 2017). There is also evidence that explicitly representing deep convection qualitatively modifies the response of summertime convective extremes to climatic changes (Kendon et al. 2014; Meredith et al. 2015; Giorgi et al. 2016; Tölle et al. 2017). For a comprehensive review see Prein et al. (2015).

However, there are limitations to CP-RCM. At these scales, shallow convection is not explicitly resolved (e.g. Soares et al. 2004; Khairoutdinov and Randall 2006; Siebesma et al. 2007) and is crucial in providing moisture and energy from the planetary boundary layer to the free atmosphere, which sustains the development of deep convection (e.g. Holloway and Neelin 2009). On one hand, summertime convective systems over land are strongly determined by the transition from shallow to deep convection (Teixeira et al. 2008; Wu 2009), and on the other hand, shallow convection is directly linked to tropical deep convection and other atmospheric phenomena like the Madden-Julian oscillation (Teixeira et al. 2011; Chen et al. 2016). Consequently, CP-RCM results are highly modeldependent. This poses problems not only for developing 
a stronger process-based understanding of the present climate but also for assessing robustness in future change signals. Also, single model experiments are not particularly robust and do not sample the range of natural variability (e.g., Tebaldi and Knutti 2007; Deser et al. 2012). Up to now assessments of uncertainties in future projections at $\mathrm{km}$-scales have not been possible due to the prevalence of single model, single realization experiments. This issue related to internal variability is moreover exacerbated at finer spatial scales where local interactions play a more prominent role (Hawkins and Sutton 2009; Deser et al. 2014). Therefore, ensemble based approaches will be needed in order to investigate convective extremes and related uncertainties in a climate change context. Further to this point, "coordinated modeling programs are crucially needed to advance parameterizations of unresolved physics and to assess the full potential of CPMs" (Prein et al. 2015).

The confluence of activities around CP-RCM at climate scales, recent field campaigns covering heavy precipitation and associated extreme events, and computational advancements, suggest that the time is right for coordinated multimodel ensemble CP-RCM experiments. In early 2016 a consortium of modeling groups from the Med-CORDEX and Euro-CORDEX initiatives submitted an application for a targeted Flagship Pilot Study (FPS, Gutowski et al. 2016) to the WCRP CORDEX (Coordinated Regional Downscaling Experiment, Giorgi et al. 2009) program (http://cordex.org/ experiment-guidelines/flagship-pilot-studies/). The aim is to develop a set of first-of-their-kind, multi-model ensemble experiments at CP-RCM scales over Euro-Mediterranean region.

However, the project is much more than a set of multimodel ensemble experiments. We aim to answer questions related to drivers of convective extremes across scales, event attribution under changing climate conditions and more (see Scientific Aims below). For example, even at convection permitting scales turbulence and other fine scale processes are not resolved and model errors will still exist. Also, computational costs limit the length of simulations which limits their utility in assessing uncertainty and trends. In this case, combined dynamical-statistical approaches and processinformed bias correction may be of use (see, Maraun et al. 2017). As mentioned previously, event detection and attribution is also just beginning and this task likely requires a more nuanced approach to interpreting projections. One promising avenue that the project will pursue is the construction of so-called "storylines" (e.g., Meredith et al. 2015; Shepherd 2014). Storylines' may be thought of as an alternative way to interpret large multi-model ensembles, where regional impacts are assessed over, for example, a range plausible scenarios of atmospheric circulation change (as and example see, Zappa and Shepherd 2017).
The FPS was awarded in spring 2016. The first annual meeting was held in November of 2016 at the Abdus Salam International Centre for Theoretical Physics in Trieste, Italy. Work began on finalizing scientific aims, developing an experimental protocol and selecting representative test cases to be examined prior to launching into expensive decade-long simulations. The primary objectives of the present manuscript are to (1) introduce the project, (2) describe its scientific goals and approaches and (3) show some preliminary results, which illustrate both the promise and peril of CP-RCM in a multi-model ensemble context.

The next section provides background information on the FPS (motivation, aims, timeline), followed by sections detailing methods and presenting preliminary results. The paper finishes with a discussion of the way forward and an invitation for contributions to the broader CP-RCM community.

\section{FPS description}

\subsection{Motivation}

Much of the motivation for the project is provided in the previous section. In short: Climate change can alter the character of convection, making extreme precipitation more extreme, and also potentially modify large-scale conditions (atmospheric circulation and stratification) that favor convection. This can then induce changes in, e.g., return periods of precipitation extremes, spatial and temporal distribution of events, the effects of convection-induced feedback processes.

The study of convective events and their evolution under human-induced climate change is therefore of particular importance, and it is also timely not least due to the following:

- Large field campaigns dedicated to the study of heavy precipitation events such as HyMeX (Ducrocq et al. 2014), and gridded high-resolution precipitation datasets (typically hourly, kilometer scale), often merging station and radar data (Wüest et al. 2010; Tabary et al. 2012; Delrieu et al. 2014) now provide a wealth of observations;

- Computer capacity and model development now allow limited-area convection-permitting climate simulations at longer time-scales (Kendon et al. 2012, 2014; Ban et al. 2014, 2015), enabling a leap in climate modeling capacity;

- Homogeneous observation data sets collected over the years can unveil emerging trend signals in most extreme precipitation events, particularly at sub-daily time scales (Westra et al. 2014), in Mediterranean coastal areas (Vau- 
tard et al. 2015) and in Alpine mountain ranges (Scherrer et al. 2016)

- Several issues linked to detection, attribution and downscaling of the very localized consequences of extreme convective events can now benefit from recent progress in advanced statistical methods combined with advances in dynamical modeling (Beaulant et al. 2011).

Convective extreme events are also a priority under the WCRP Grand Challenge on weather and climate extremes, because they carry both society-relevant and scientific challenges that can be tackled in the coming years.

The proposed work in the Convection FPS also reflects a number of criteria identified by the CORDEX-FPS Scientific Advisory Team (SAT) such as: (1) run RCMs at a broad range of resolutions, down to convection-permitting; (2) promote side-by-side experimental design and evaluations of both statistical and dynamical downscaling techniques at scales more typical of vulnerability-impacts-assessment applications; (3) design targeted experiments aimed at investigating specific regional processes and circulations; (4) investigate the importance of regional scale forcings; (5) compile and use high quality, high resolution (both spatial and temporal), multi-variable observation datasets for model validation and analysis of processes.

The makeup of the consortium is diverse, both institutionally and with respect to expertise (Table 1). Though many participants come from climate background, others bring significant NWP experience to the challenge. The FPS mobilizes the Euro-CORDEX and Med-CORDEX communities but is also open to new partners who bring fresh perspectives and expertise.

\subsection{Scientific questions}

The project was conceived with three general and openended scientific questions to allow some flexibility in the analyses while also providing sufficient structure to keep the consortium working towards some common goals. The general aims and specific challenges/questions can be summarized as:

1. How do convective events and associated damaging phenomena (heavy precipitation, wind storms, flash-floods) respond to changing climate conditions in different climatic regions of Europe?

- Identify trends in intensity, scale and duration in past observations, in underlying processes, and understand how these are simulated by convection permitting RCMs;
- Explain major events in the context of climate change, via "storylines" of individual events under different climatic conditions, but conditional on a fixed state of the large-scale atmospheric circulation (e.g., Meredith et al. 2015; Shepherd 2014) in addition to a more robust assessment of uncertainties using an ensemble-based approach;

- Investigate life cycles of convective phenomena and related processes in the context of a changing climate;

- Identify the added-value of convection-permitting models in simulating such trends with respect to standard resolution regional climate models, including the investigation of relevant underlying processes;

- Include additional processes/phenomena such as high altitude snow and related hydro climatic impacts, mesoscale processes such as low-level wind convergence, orographic interactions, landatmosphere interactions and hydrological impacts;

- Identify the added value of CP-RCM scenario simulation;

2. Does an improved representation of convective processes and precipitation at convection permitting scales lead to upscaled added value?

- How improved are CP-RCM aggregated precipitation statistics compared to lower-resolution models up to the resolution of GCMs?

- Do CP-RCMs and parameterized models have the same temperature-precipitation intensity relation (as formulated in Lenderink and van Meijgaard 2008)?

- Can CP-RCMs serve as reference to improve convection parameterizations, from shallow to deep?

- Are there differences in the representation of key feedback processes between parameterized and explicit convection (e.g. Hohenegger et al. 2009)?

- Are there improvements in the aggregate statistics of other near-surface variables such as temperature and wind?

3. Is it possible to augment costly convection-permitting experiments with physically defensible statistical downscaling approaches such as "convection emulators" that mimic CP-RCMs and are fed by output of conventionalscale RCMs? 
Table 1 List of contributors

\begin{tabular}{|c|c|c|c|c|c|c|c|c|}
\hline & Contributor's ID & Contact person & Model & Institute & Testcases & $\begin{array}{l}\text { Climate } \\
\text { scenario } \\
\text { simulation }\end{array}$ & $\begin{array}{l}\text { Nudging } \\
\text { inner/outer } \\
\text { domain }\end{array}$ & $\begin{array}{l}\text { Resolution of } \\
\text { intermediate nest }\end{array}$ \\
\hline 1 & RegCM4- ICTP & Erika Coppola & RegCM4 & $\begin{array}{l}\text { Abdus Salam } \\
\text { Internatinal } \\
\text { Centre for } \\
\text { Theoretical } \\
\text { Physics-Earth } \\
\text { System Physics }\end{array}$ & $\sqrt{ }$ & $\sqrt{ }$ & $\mathrm{No} / \mathrm{No}$ & $\begin{array}{l}\text { 0.11 Euro-Cordex } \\
\text { domain }\end{array}$ \\
\hline 2 & $\begin{array}{l}\text { RegCM4- } \\
\text { DHMZ }\end{array}$ & Ivan Güttler & RegCM4 & $\begin{array}{l}\text { Croatian Mete- } \\
\text { orological and } \\
\text { Hydrological } \\
\text { Service }\end{array}$ & $\sqrt{ }$ & $\sqrt{ }$ & $\mathrm{No} / \mathrm{No}$ & $\begin{array}{l}\text { 0.11 Euro-Cordex } \\
\text { domain }\end{array}$ \\
\hline 3 & RegCM4-CUNI & Michal Belda & RegCM4 & $\begin{array}{l}\text { Univerzita } \\
\text { Karlova, } \\
\text { Matematicko- } \\
\text { fyzikální } \\
\text { fakulta, Praha }\end{array}$ & $\sqrt{ }$ & $\sqrt{ }$ & $\mathrm{No} / \mathrm{No}$ & $\begin{array}{l}\text { 0.11 Euro-Cordex } \\
\text { domain }\end{array}$ \\
\hline 4 & CCLM-JLU & Merja Toelle & CCLM5-0-9 & $\begin{array}{l}\text { Justus-Liebig } \\
\text { University } \\
\text { of Giessen, } \\
\text { Department } \\
\text { of Geography, } \\
\text { Climatol- } \\
\text { ogy, Climate } \\
\text { Dynamics } \\
\text { and Climate } \\
\text { Change }\end{array}$ & $\sqrt{ }$ & $\sqrt{ }$ & $\mathrm{No} / \mathrm{No}$ & $\begin{array}{l}\text { No NEST, direct } \\
\text { from } 0.75 \\
\text { ERAINT }\end{array}$ \\
\hline 5 & CCLM-KIT & $\begin{array}{l}\text { Hans-Juergen } \\
\text { Panitz }\end{array}$ & CCLM5-0-9 & $\begin{array}{l}\text { Karlsruhe } \\
\text { Institute of } \\
\text { Technology }\end{array}$ & $\sqrt{ }$ & $\sqrt{ }$ & $\mathrm{No} / \mathrm{No}$ & $\begin{array}{l}0.22 \text { Euro-Cordex } \\
\text { domain }\end{array}$ \\
\hline 6 & CCLM-WEGC & Marie Piazza & CCLM5-0-9 & $\begin{array}{l}\text { Wegener Center } \\
\text { for Climate and } \\
\text { Global Change, } \\
\text { University of } \\
\text { Graz }\end{array}$ & $\sqrt{ }$ & $\sqrt{ }$ & $\mathrm{No} / \mathrm{No}$ & $\begin{array}{l}0.11 \text { Euro-Cordex } \\
\text { domain }\end{array}$ \\
\hline 7 & COSMO-KIT & Samiro Khodayar & CCLM5-0-9 & $\begin{array}{l}\text { Karlsruhe } \\
\text { Institute of } \\
\text { Technology }\end{array}$ & $\sqrt{ }$ & & $\mathrm{No} / \mathrm{No}$ & $\begin{array}{l}\text { 0.11 Euro-Cordex } \\
\text { domain }\end{array}$ \\
\hline 8 & COSMO-CMCC & Mario Raffa & CCLM5-0-9 & $\begin{array}{l}\text { Euro- Mediter- } \\
\text { ranean Center } \\
\text { on Climate } \\
\text { Change }\end{array}$ & $\sqrt{ }$ & $\sqrt{ }$ & $\mathrm{No} / \mathrm{No}$ & $\begin{array}{l}0.22 \text { Euro-Cordex } \\
\text { domain }\end{array}$ \\
\hline 9 & CCLM-ZAMG & Ivonne Anders & CCLM5-0-9 & $\begin{array}{l}\text { Central Institute } \\
\text { for Meteor- } \\
\text { ology and } \\
\text { Geodynamics, } \\
\text { ZAMG }\end{array}$ & & $\sqrt{ }$ & $\mathrm{No} / \mathrm{No}$ & $\begin{array}{l}0.11 \text { Euro-Cordex } \\
\text { domain }\end{array}$ \\
\hline 10 & CCLM-GUF & Bodo Ahrens & CCLM & $\begin{array}{l}\text { Goethe Univer- } \\
\text { sity Frankfurt } \\
\text { am Main }\end{array}$ & & $\sqrt{ }$ & No/No & $\begin{array}{l}0.11 \text { Euro-Cordex } \\
\text { Domain }\end{array}$ \\
\hline 11 & CCLM-ETH & Nikolina Ban & CCLM & $\begin{array}{l}\text { Institut für } \\
\text { Atmosphäre } \\
\text { und Klima, } \\
\text { ETH Zürich }\end{array}$ & & $\sqrt{ }$ & $\mathrm{No} / \mathrm{No}$ & $\begin{array}{l}\text { 0.11 Euro-Cordex } \\
\text { domain }\end{array}$ \\
\hline 12 & WRF-UHOH & Josipa Milovac & WRF & $\begin{array}{l}\text { University of } \\
\text { Hohenheim, } \\
\text { Germany }\end{array}$ & $\sqrt{ }$ & $\sqrt{ }$ & $\mathrm{No} / \mathrm{No}$ & $\begin{array}{l}\text { 0.11 Euro-Cordex } \\
\text { domain }\end{array}$ \\
\hline
\end{tabular}


Table 1 (continued)

\begin{tabular}{|c|c|c|c|c|c|c|c|c|}
\hline & Contributor's ID & Contact person & Model & Institute & Testcases & $\begin{array}{l}\text { Climate } \\
\text { scenario } \\
\text { simulation }\end{array}$ & $\begin{array}{l}\text { Nudging } \\
\text { inner/outer } \\
\text { domain }\end{array}$ & $\begin{array}{l}\text { Resolution of } \\
\text { intermediate nest }\end{array}$ \\
\hline 13 & WRF-WEGC & Heimo Truhetz & WRF & $\begin{array}{l}\text { Wegener Center } \\
\text { for Climate and } \\
\text { Global Change, } \\
\text { University of } \\
\text { Graz }\end{array}$ & $\sqrt{ }$ & $\sqrt{ }$ & $\mathrm{No} / \mathrm{No}$ & $\begin{array}{l}\text { 0.11 Euro-Cordex } \\
\text { domain }\end{array}$ \\
\hline 14 & $\begin{array}{l}\text { WRF-AUTH- } \\
\text { MC }\end{array}$ & Eleni Katragkou & WRF & $\begin{array}{l}\text { Aristotle } \\
\text { University of } \\
\text { Thessaloniki, } \\
\text { Department of } \\
\text { Meteorology \& } \\
\text { Climatology }\end{array}$ & $\sqrt{ }$ & $\sqrt{ }$ & $\mathrm{No} / \mathrm{No}$ & $\begin{array}{l}\text { 0.11 Euro-Cordex } \\
\text { domain }\end{array}$ \\
\hline 15 & WRF-FZJ-IBG3 & Klaus Goergen & WRF & $\begin{array}{l}\text { Research Centre } \\
\text { Jülich, Institute } \\
\text { of Bio- and } \\
\text { Geosciences } \\
\text { (Agrosphere, } \\
\text { IBG-3) }\end{array}$ & $\sqrt{ }$ & $\sqrt{ }$ & $\mathrm{No} / \mathrm{No}$ & $\begin{array}{l}\text { 0.11 Euro-Cordex } \\
\text { domain }\end{array}$ \\
\hline 16 & WRF-IPSL & Lluís Fita Borrell & WRF & $\begin{array}{l}\text { The Institute } \\
\text { Pierre Simon } \\
\text { Laplace, Paris }\end{array}$ & $\sqrt{ }$ & $\sqrt{ }$ & $\mathrm{No} / \mathrm{No}$ & $\begin{array}{l}\text { 0.11 Euro-Cordex } \\
\text { domain }\end{array}$ \\
\hline 17 & WRF-BCCR & $\begin{array}{l}\text { Stefan } \\
\text { Sobolowski }\end{array}$ & WRF & $\begin{array}{l}\text { Bjerknes Centre } \\
\text { for Climate } \\
\text { Research }\end{array}$ & $\sqrt{ }$ & $\sqrt{ }$ & $\mathrm{No} / \mathrm{No}$ & $\begin{array}{l}\text { 0.11 Euro-Cordex } \\
\text { domain }\end{array}$ \\
\hline 18 & WRF-UNICAN & Jesus Fernandez & WRF & $\begin{array}{l}\text { Santander Mete- } \\
\text { orology Group, } \\
\text { Universidad } \\
\text { de Cantabria, } \\
\text { Dept. Applied } \\
\text { Mathematics } \\
\text { and Comp. Sci. }\end{array}$ & $\sqrt{ }$ & $\sqrt{ }$ & $\mathrm{No} / \mathrm{No}$ & $\begin{array}{l}\text { 0.11 Euro-Cordex } \\
\text { domain }\end{array}$ \\
\hline 19 & WRF-IDL & $\begin{array}{l}\text { Rita Margarida } \\
\text { Cardoso }\end{array}$ & WRF & $\begin{array}{l}\text { Instituto Dom } \\
\text { Luiz, Faculdade } \\
\text { de Ciências da } \\
\text { Universidade } \\
\text { de Lisboa }\end{array}$ & $\sqrt{ }$ & $\sqrt{ }$ & $\mathrm{No} / \mathrm{No}$ & $\begin{array}{l}\text { 0.11 Euro-Cordex } \\
\text { domain }\end{array}$ \\
\hline 20 & WRF-CICERO & Louis Marelle & WRF & $\begin{array}{l}\text { Center for } \\
\text { International } \\
\text { Climate and } \\
\text { Environmental } \\
\text { Research - Oslo }\end{array}$ & $\sqrt{ }$ & $\sqrt{ }$ & $\mathrm{No} / \mathrm{No}$ & $\begin{array}{l}\text { 0.11 Euro-Cordex } \\
\text { domain }\end{array}$ \\
\hline 21 & WRF-L-IPSL & Robert Vautard & WRF & $\begin{array}{l}\text { The Institute } \\
\text { Pierre Simon } \\
\text { Laplace, Paris }\end{array}$ & & $\sqrt{ }$ & $\mathrm{No} / \mathrm{No}$ & $\begin{array}{l}\text { 0.11 Euro-Cordex } \\
\text { domain }\end{array}$ \\
\hline 22 & WRF-GIUB & $\begin{array}{l}\text { Andrey Mar- } \\
\text { tynov }\end{array}$ & WRF & $\begin{array}{l}\text { Institute of } \\
\text { Geography and } \\
\text { Oeschger Cen- } \\
\text { tre University } \\
\text { of Bern Bern, } \\
\text { Switzerland }\end{array}$ & & $\sqrt{ }$ & $\mathrm{No} / \mathrm{No}$ & $\begin{array}{l}\text { 0.11 Euro-Cordex } \\
\text { domain }\end{array}$ \\
\hline 23 & WRF-NOA & $\begin{array}{c}\text { Theodore M. } \\
\text { Giannaros }\end{array}$ & WRF & $\begin{array}{l}\text { National } \\
\text { Observatory } \\
\text { of Athens, } \\
\text { Institute for } \\
\text { Environmental } \\
\text { Research and } \\
\text { Sustainable } \\
\text { Development }\end{array}$ & & $\sqrt{ }$ & $\mathrm{No} / \mathrm{No}$ & $\begin{array}{l}\text { 0.11 Euro-Cordex } \\
\text { domain }\end{array}$ \\
\hline
\end{tabular}


Table 1 (continued)

\begin{tabular}{|c|c|c|c|c|c|c|c|c|}
\hline & Contributor's ID & Contact person & Model & Institute & Testcases & $\begin{array}{l}\text { Climate } \\
\text { scenario } \\
\text { simulation }\end{array}$ & $\begin{array}{l}\text { Nudging } \\
\text { inner/outer } \\
\text { domain }\end{array}$ & $\begin{array}{l}\text { Resolution of } \\
\text { intermediate nest }\end{array}$ \\
\hline 24 & REMO-GERICS & Kevin Sieck & REMO2017 & $\begin{array}{l}\text { Climate Service } \\
\text { Center Ger- } \\
\text { many }\end{array}$ & $\sqrt{ }$ & $\sqrt{ }$ & $\mathrm{No} / \mathrm{No}$ & $\begin{array}{l}0.11 \text { Euro-Cordex } \\
\text { domain }\end{array}$ \\
\hline 25 & HCLIM-KNMI & Hylke de Vries & $\begin{array}{l}\text { HCLIM38- } \\
\text { AROME }\end{array}$ & $\begin{array}{l}\text { The Royal } \\
\text { Netherlands } \\
\text { Meteorological } \\
\text { Institute }\end{array}$ & $\sqrt{ }$ & $\sqrt{ }$ & No/No & $\begin{array}{l}\text { 0.11 Euro-Cordex } \\
\text { domain }\end{array}$ \\
\hline 26 & HCLIM-METNo & Andreas Dobler & $\begin{array}{l}\text { HCLIM38- } \\
\text { AROME }\end{array}$ & $\begin{array}{l}\text { The Norwegian } \\
\text { Meteorological } \\
\text { Institute }\end{array}$ & $\sqrt{ }$ & $\sqrt{ }$ & $\mathrm{No} / \mathrm{No}$ & $\begin{array}{l}\text { 0.11 Euro-Cordex } \\
\text { domain }\end{array}$ \\
\hline 27 & HCLIM-SMHI & Danijel Belusic & $\begin{array}{l}\text { HCLIM38- } \\
\text { AROME }\end{array}$ & $\begin{array}{l}\text { Swedish Mete- } \\
\text { orological and } \\
\text { Hydrological } \\
\text { Institute }\end{array}$ & $\sqrt{ }$ & $\sqrt{ }$ & $\mathrm{No} / \mathrm{No}$ & $\begin{array}{l}\text { 0.11 Euro-Cordex } \\
\text { domain }\end{array}$ \\
\hline 28 & AROME-CNRM & Samuel Somot & AROME41t1 & $\begin{array}{l}\text { CNRM-MeteoF- } \\
\text { rance }\end{array}$ & $\sqrt{ }$ & $\sqrt{ }$ & $\mathrm{No} / \mathrm{Yes}$ & $\begin{array}{l}\text { 0.11 Med-Cordex } \\
\text { domain }\end{array}$ \\
\hline 29 & MOLOCH-CNR & Silvio Davolio & MOLOCH & $\begin{array}{l}\text { Institute of } \\
\text { Atmospheric } \\
\text { Sciences and } \\
\text { Climate, ISAC- } \\
\text { CNR }\end{array}$ & $\sqrt{ }$ & & No/No & $\begin{array}{l}\text { 0.11 Euro-Cordex } \\
\text { domain }\end{array}$ \\
\hline 30 & UM10.1-MOHC & Lizzie Kendon & UM10.1 & $\begin{array}{l}\text { Met Office Had- } \\
\text { ley Centre }\end{array}$ & & $\sqrt{ }$ & $\mathrm{No} / \mathrm{No}$ & $\begin{array}{l}\text { No NEST, direct } \\
\text { from } 0.75 \\
\text { ERAINT }\end{array}$ \\
\hline
\end{tabular}

- Can the variability of local-scale convective precipitation be sensibly predicted by statistically downscaling $0.11^{\circ}$ area-averages of variables that are typically provided by RCMs?

- Can the corresponding response to climate change be sensibly predicted by corresponding $0.11^{\circ}$ resolution RCM predictors?

- Can statistical methods be advanced to include temporal discretization that elucidates sub-daily rainfall;

- Can these approaches be expanded to include temperature and wind?

\subsection{Expected impact}

- Improved understanding of mechanisms and factors that influence location, intensity, frequency and extent of convective precipitation events under changing climate conditions;

- Better constrained estimates of future changes in convective extremes and associated processes, phenomena and feedbacks across Euro-Mediterranean regions;

- Bridge the spatial scale gap between regional climate models and impact models (hydrological models, ecosystem models, etc.)
- Provide added value for the decision-making process through analysis of risks and opportunities associated with changes in extreme convective events.

\subsection{Timeline/experiment protocol}

\subsubsection{7: first set of simulations}

RCM simulations will be run at convection-permitting resolutions for selected test periods

- Mandatory domain centered on the Alpine chain $\left(1^{\circ}-17^{\circ}\right.$ longitude East, $40^{\circ}-50^{\circ}$ latitude North) (Fig. 1);

- Individual model sub-groups coordinate multi-physics options internally and conduct short tests;

- Perform test case study experiments with model systems run in weather like (WL) and climate mode (CM), see Methods for more details.

- Finalize the definition of the other FPS domains.

\subsubsection{8: begin ERA-Interim evaluation simulations}

- Perform simulations that will systematically assess the ability of the CP-RCMs to represent the present climate period chosen to overlap with recent high resolution 


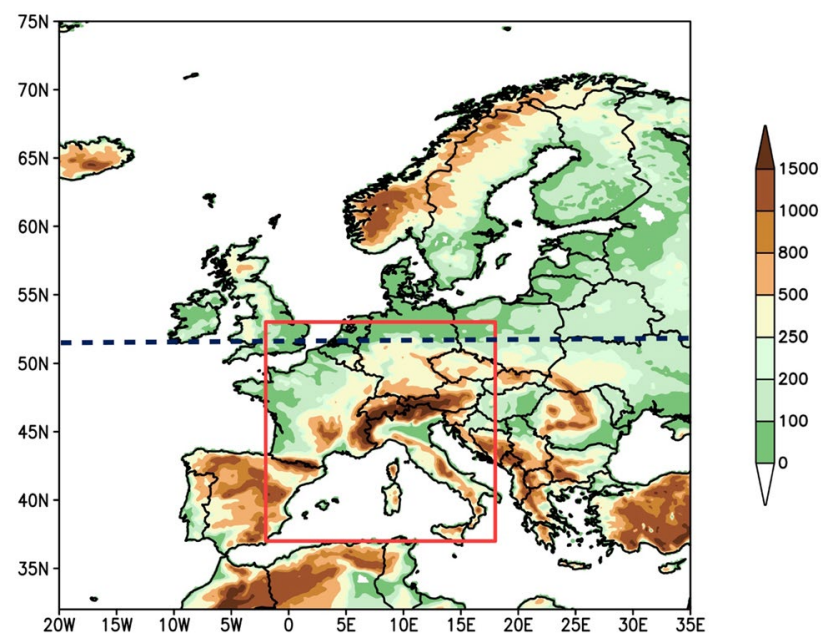

Fig. 1 Euro-CORDEX domain at $0.11^{\circ}$ resolution with highlighted red box for FPS mandatory domain. The blue dashed line represents the Northern boundary of the Med-CORDEX domain

observation campaigns: 2000-2014 (minimum 10 years), ERA-Interim.

- Develop a statistical convection model that will be employed to identify mechanisms of long-term changes in convective precipitation and serve to evaluate the representation of underlying processes, assess added value and emulate convective precipitation.

\subsubsection{9-2021: third set of simulations, event interpretation, detailed analyses and intercomparisons}

- Scenario simulations (10 year time slices of selected CMIP5 GCM projections, CMIP6 if available; periods: 1996-2005, 2041-50, 2090-99 (HIST and RCP8.5)

- Additional simulations focusing on extreme events under present and future conditions for the purpose of event interpretation;

- open access to the CP-RCM output data through the ESGF

- Link to the impact community: Impact models forced by CP-RCM output for past and future climate periods, and compared with recent databases (Llasat et al. 2013).

\section{Methods}

An ensemble of CP-RCMs has been created with each model coming from one of the European RCM groups. The models and institutes participating to the FPS effort are reported in Table 1, and more contributors are foreseen in the near future. All these models will produce the set of experiments mentioned above and for the purpose of this paper a set of test case simulations have been completed with the main purpose of testing this nascent multi-model ensemble (MME). The purpose of this initial set of experiments is to:

- reproduce convection explicitly at convection permitting scales (many models never carried out such an exercise before) and assess the model performance in such experiments;

- assess what can be expected from climate-type simulations with CP-RCMs with respect to heavy precipitation (HP) events;

- set up a test platform for new models entering the project.

For this particular exercise three case studies have been identified in what we defined as two modes:

1. The weather like initialization (WL).

2. The climate mode initialization (CM).

For each case study ERA-Interim is used to provide boundary conditions (Dee et al. 2011).

At present there are 27 total contributors to the FPS with 23 making contributions to the case studies (Table 1). Due to computational constraints not all contributors were able to simulate all three cases. Therefore, the analyzed ensemble size is 21 for cases 1,2 and 18 for case 3 (18 contributors simulated all 3 test cases, 2 contributors only simulated case 2, 2 contributors only simulated case 1 , and 1 contributor only simulated cases 1 and 2).

20 of the 23 contributors who simulated the case studies used the same nesting strategy, which was to nest (oneway) the convection permitting domain within a $0.11^{\circ}$ panEuropean domain with ERA-Interim driving the LBCs (see Table 1). This nesting procedure has been performed for each of the modes (WL and CM) separately and exactly for the respective simulation period, leading to different LBCs for CM respectively WL modes. However, teams were also allowed freedom to pursue alternative nesting strategies, which could be used as departure points for investigating the possibility for direct downscaling from e.g., ERA-Interim scales to convection permitting scales and the effects of internal variability developing in the intermediate domain. A few of the CCLM teams chose these different strategies, which clearly impacted the results in interesting ways. One contributor (CCLM-5-0-9-JLU) directly downscaled from ERA-Interim to $\sim 3 \mathrm{~km}$ for both simulations. Two others (CCLM-5-0-9-KIT and COSMO-CMCC) first downscaled ERA-Interim to an intermediate pan-European domain $\left(0.22^{\circ}\right)$ for a long-term ( $>15$ years) and then used output from this for the convection permitting simulations after the fact. These two approaches have the same net effect, which is to impose identical lateral atmospheric boundary forcing for both the WL and CM simulations. This tightly constrains 
the forcing at the lateral boundaries and should, in principle, limit the development of internal variability.

For each contribution WL and CM simulations follow the same nesting procedure, however the WL experiments are initialized 24-48 $\mathrm{h}$ before the HP event while the CM ones are initialized 1 month before the event. The acronyms of the three case studies and the initialization procedures are reported in Table 2 for both the WL and CM cases. This is not meant to be a repetition of similar exercises carried out by the the NWP community (though in this instance the ensemble is much larger than any previously aggregated). It is rather intended as a first check of the ensemble and the individual models (especially new ones) before the consortium launches into the planned long-term climate simulations. It is worth noting that only a preliminary diagnostic analysis of the ensemble model performance is presented here, and a full-fledged, detailed, evaluation of the results is out of the scope, (which is presented in other papers of the special issue). The intention of this paper is primarily to introduce the FPS, and to detail the approach, focusing on challenges and potential.

Observational data for the three test cases are obtained from a variety of sources. Unlike analyses at coarser resolution, long, 3D, gridded, high spatial and temporal resolution datasets do not exist. Although efforts to create extended high resolution 2D reanalyses have begun (Landelius et al. 2016). As a result analyses at convection permitting scales currently must rely on spatially limited, in-situ datasets. For the three test cases presented in this manuscript we employed observational data from the following sources: (1) HyMex-IOP16 (Intense Observation Period) precipitation data from Meteo France; (2) WegenerNet data from The Wegener Centre at the University of Graz, Austria; (3) MeteoGroup Switzerland.

\subsection{Preliminary results}

For each of the three test case studies and for both experiment configurations, the analysis focuses here on the total accumulated precipitation for the whole domain during the event as defined in Table 2 and on the time series of hourly and $12 \mathrm{~h}$ accumulated precipitation in the region of maximum precipitation as indicated by observations.

\subsubsection{Case 1}

The first case (Case 1), referred to as HyMeX-IOP16 in Table 2, is a HP event occurred during the HyMeX measurement campaign in September-November 2012 (Ducrocq et al. 2014). The event is documented in detail by Duffourg et al. (2016) and Martinet et al. (2017), and it consists of slow propagating mesoscale convective systems (MCSs) associated with the evolution of a trough interacting with an upper-level low centered over the Iberian Peninsula which induced warm, moist and unstable southerly flow in the lower troposphere over the western Mediterranean. The interaction of the upper-level forcing with the warm lowlevel air mass increased instability and induced the deepening of a depression over the Gulf of Lion, favoring in turn the formation of MCSs that affected Southern France and Northern Italy between 25 and 27 Oct, 2012. According to the station observations collected during the field campaign (Ducrocq et al. 2014, http://hoc.sedoo.fr for HyMeX database) three regions were mainly affected by heavy precipitation. Two areas were in Southern France-referred to as CV1 and CV2 and indicating, respectively, the western and eastern parts of the Cévennes-Vivarais (CV) observation site during the HyMeX campaign (see Fig. 1 in Ducrocq et al. 2014). The third affected area was Liguria-Tuscany one (LT, Fig. 1 in Ducrocq et al. 2014). These three regions are highlighted in Fig. 2a with red, green and blue squares; here the observed total accumulated precipitation maxima were, respectively, around 170,140, and $250 \mathrm{~mm}$. The same figure shows the ensemble average of the $\mathrm{WL}$ and $\mathrm{CM}$ experiments in panels $\mathrm{b}$ and $\mathrm{c}$, respectively, along with all the individual ensemble members (WL/CM in the left/right columns).

As a general comment, we can observe how the locations of the three maxima are generally well captured by the WL
Table 2 List of acronyms of the three test cases and initialization procedure

\begin{tabular}{llll}
\hline Case & Acronym & Initialization procedure & Analyzed time window \\
\hline 1 & HymexIOP16 & Starting date (WL): 2012-10-23 & 23 Oct 2012 00:00 \\
& & Ending date (WL): 2012-10-28 & - \\
& Starting date (CM): 2012-10-01 & 28 Oct 2012 00:00 \\
& Ending date (CM): 2012-11-01 & \\
& & Starting date (WL): 2009-06-20 & 22 Jun 2009 00:00 \\
& AUSTRIA & Ending date (WL): 2009-06-27 & - \\
& & Starting date (CM): 2009-06-01 & 25 Jun 2009 00:00 \\
& Ending date (CM): 2009-07-01 & \\
& FOEHN & Starting date (WL): 2014-11-02 & 3 Nov 2014 00:00 \\
& & Ending date (WL): 2014-11-07 & - \\
& & Starting date (CM): 2014-10-01 & 7 Nov 2014 00:00 \\
& & Ending date (CM): 2014-11-07 & \\
\hline
\end{tabular}




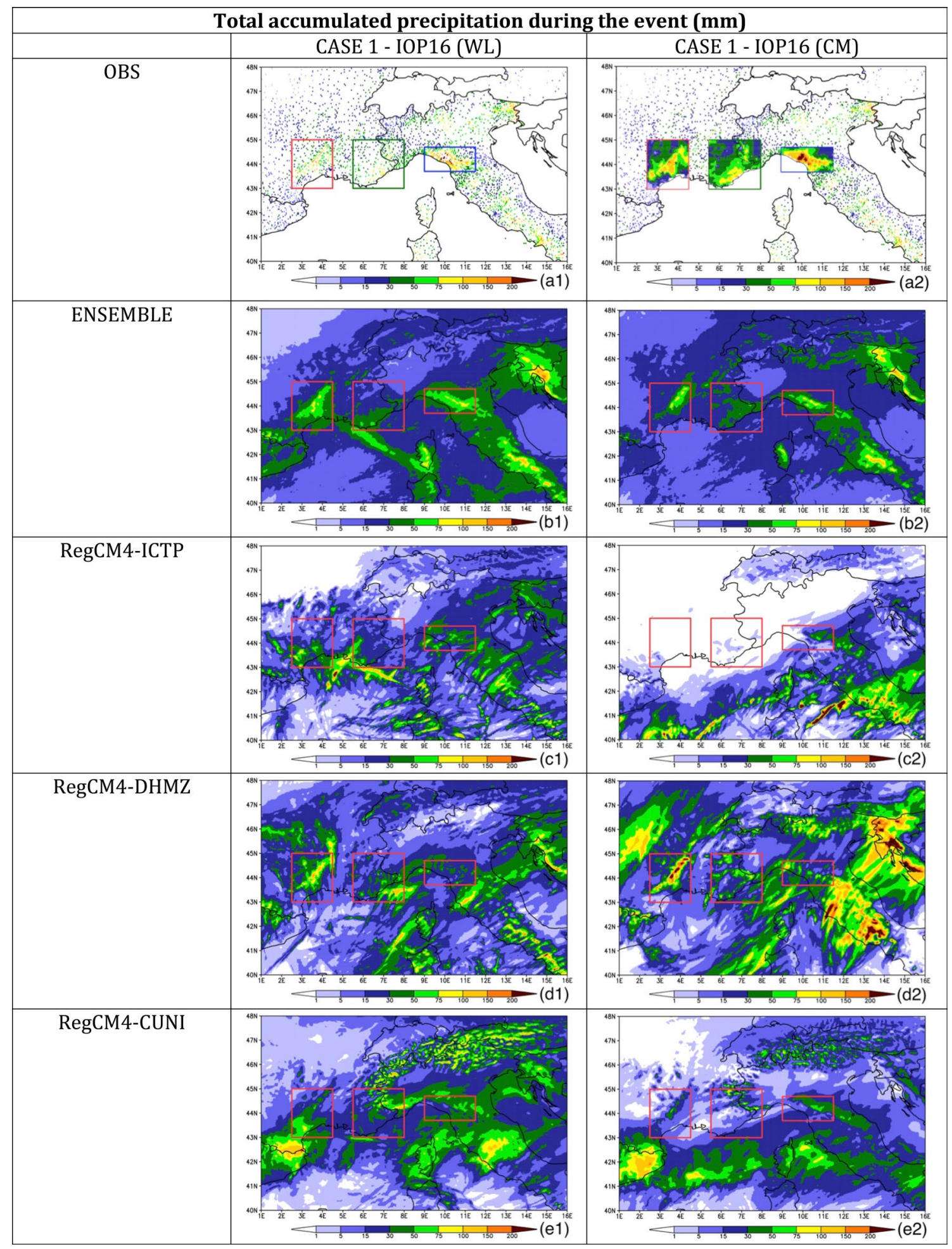

Fig. 2 Case 1-HyMeX-IOP16. Total accumulated precipitation (mm) for observations, multi-model ensemble mean (MMEM) and each ensemble member. Results are shown for the models run in WL mode (left) and in CM (right). Red, green and blue boxes on panels (a1) and (a2) indicate specific areas of interest. a2 Shows an interpolation of the observed precipitation field 


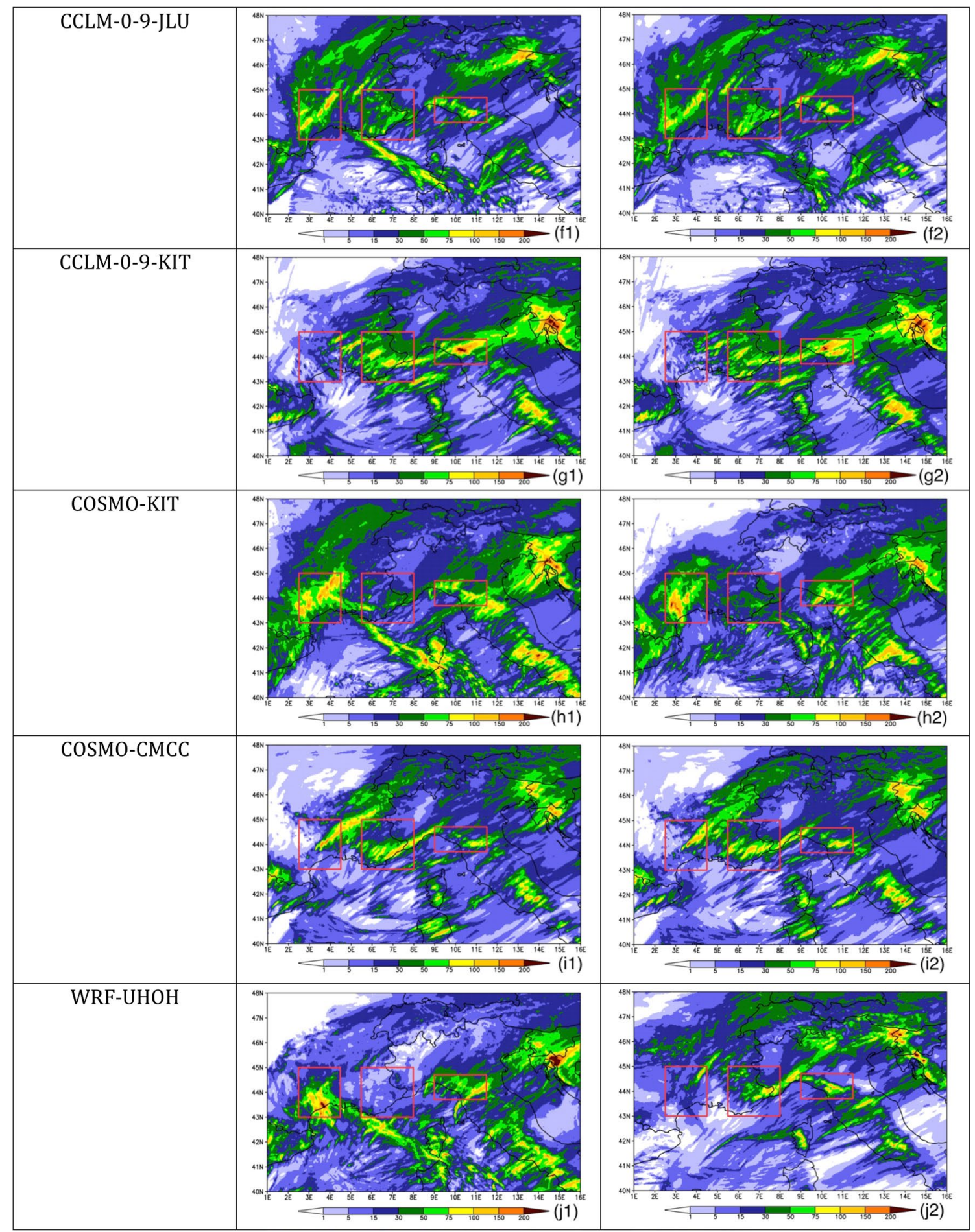

Fig. 2 (continued)

ensemble, although the precipitation intensities are lower than observed. For the $\mathrm{CM}$ ensemble, the average location of the three events is still well represented but the underestimation is more pronounced. This ensemble behavior is reflected in the individual realizations, where for each $\mathrm{CM}$ simulation the intensity of maximum precipitation is lower than the corresponding WL one, although some members of the ensemble still show a maximum precipitation higher than observed.

A more quantitative analysis is reported in Table 3, where for each model and for both modes the spatial correlation of the total accumulated precipitation in the 3 boxes is 


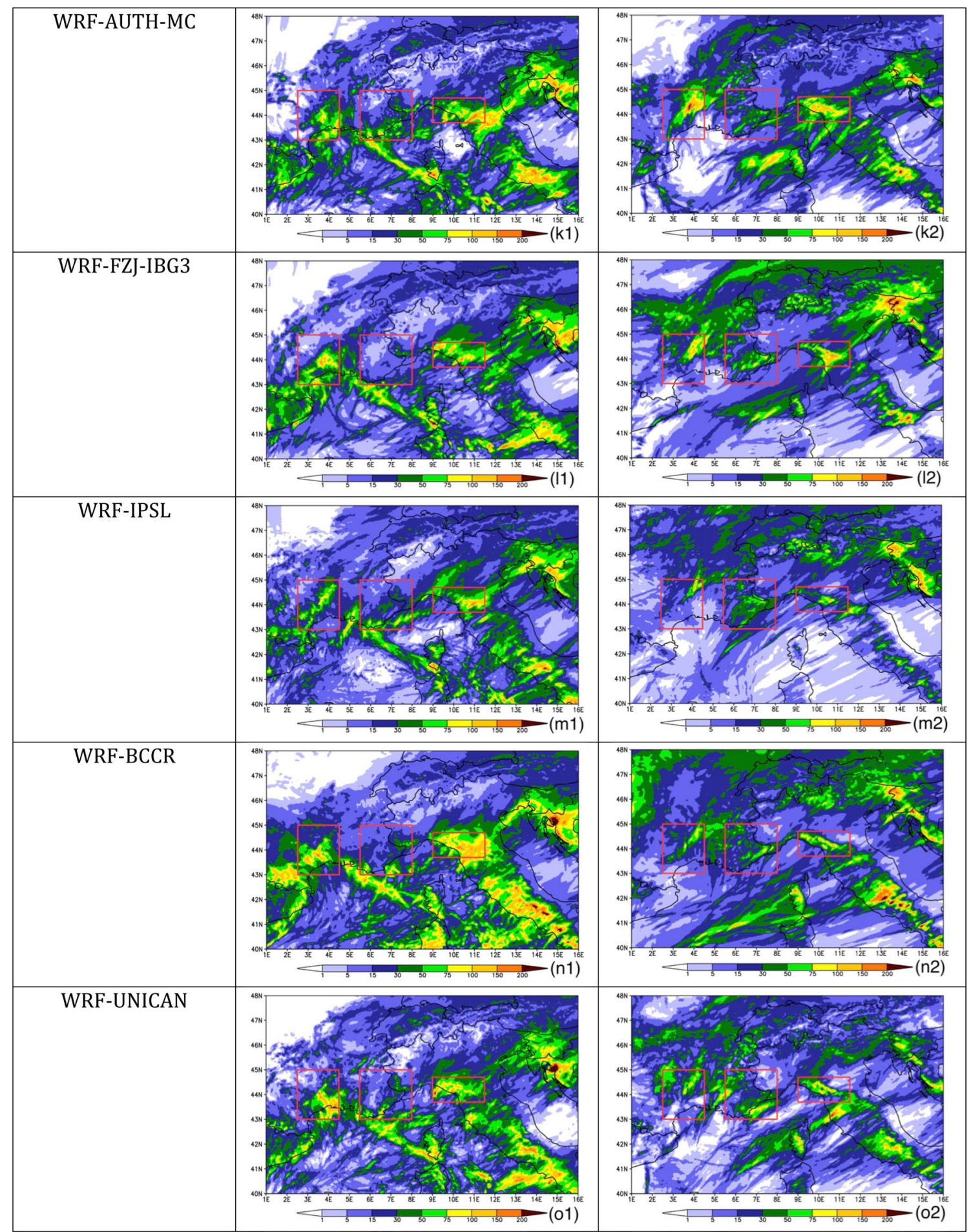

Fig. 2 (continued)

computed between the observed interpolated field (Fig. 2, a2) and the model output. If we consider a threshold of 0.5 for a reasonable correlation score, $60 \%$ of the WL simulations in the CV1 regions have a correlation higher than 0.5 , $30 \%$ in CV2 and 20\% in LT regions. For the CM simulation the percentages drop to $23 \%$ and $14 \%$ in the first two regions but increase to $57 \%$ in the LT regions.

In Fig. 3a, d, and $g$ the spatial correlation of the 12 hourly accumulated precipitation is reported over the duration of the event for each model and for both WL and CM 


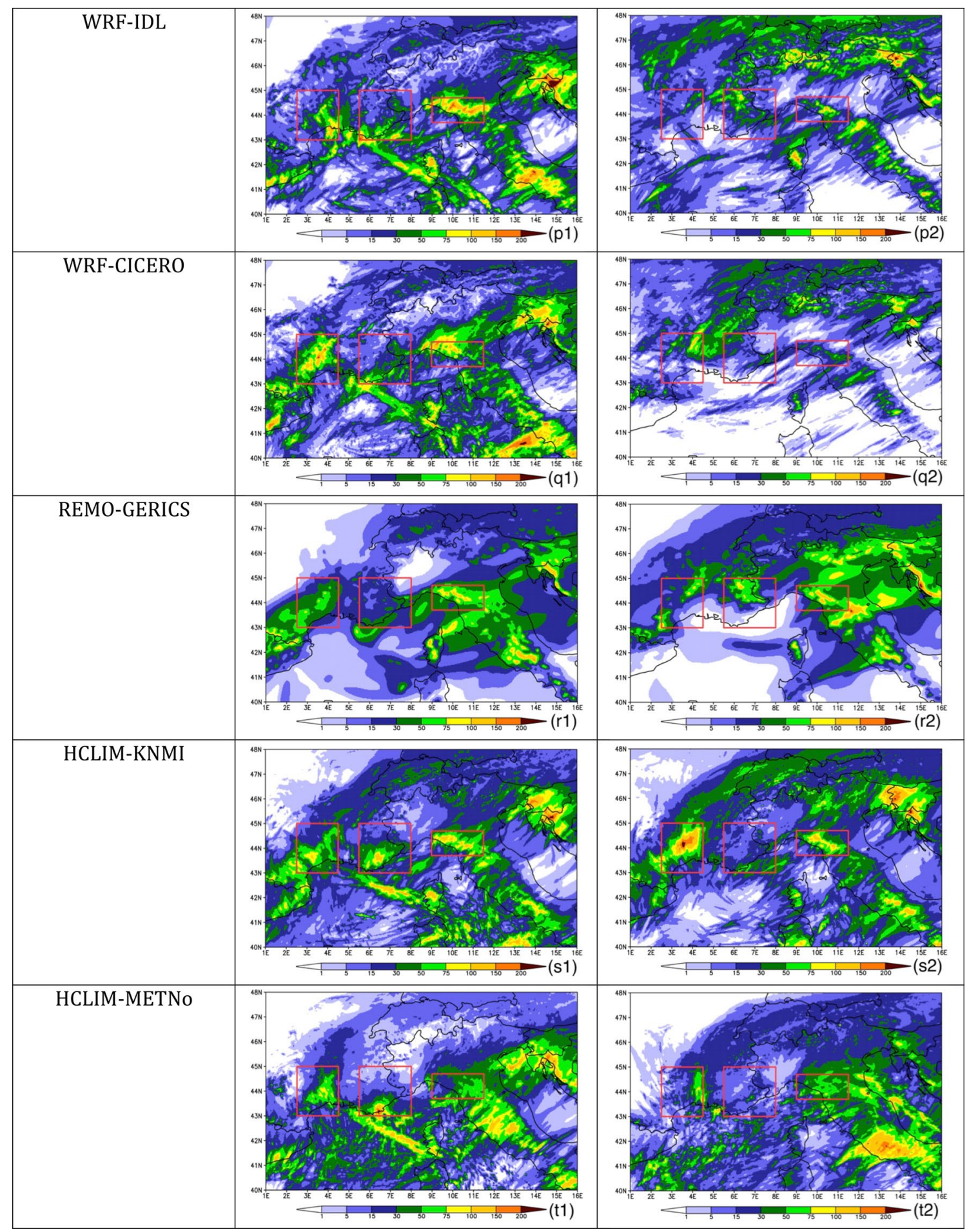

Fig. 2 (continued)

simulations. The value of the observed 12 hourly accumulated precipitation is reported too, as an indication of the time evolution of the event across the 3 regions. For each box the peak model skill is reached near the peak of the event and the percentage of models that are above
0.5 correlation value remains similar to those reported in Table 3 as does the ratio between CM and WL. These indicate that the ability of the models to follow the time evolution of the event is similar in both WL and CM mode. 


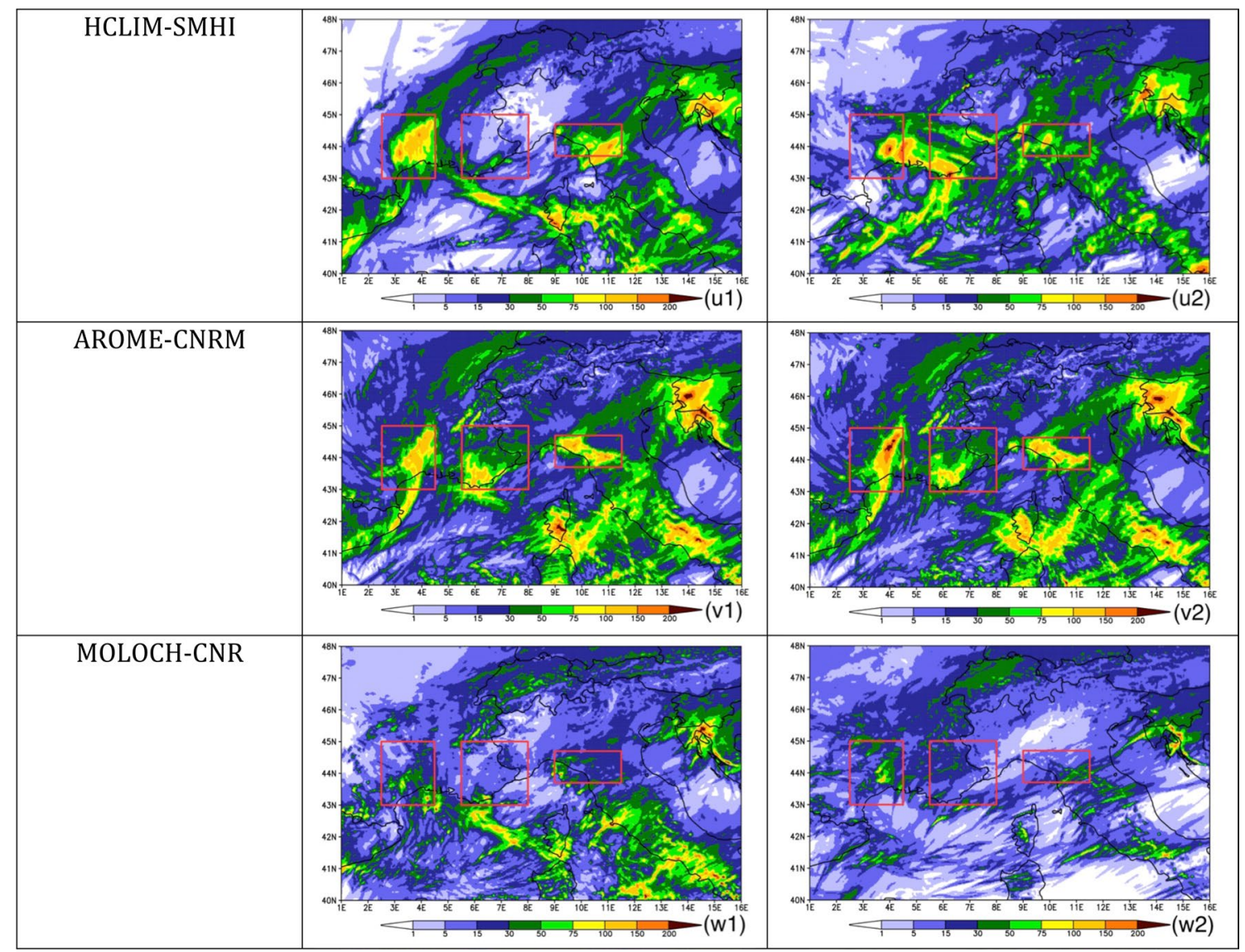

Fig. 2 (continued)

Concerning the timing and intensity of the events in the 3 subregions, the hourly accumulated precipitation averaged over each box is plotted for each WL and CM ensemble member in Fig. 3b, e, and h, along with the observations and the WL and CM ensemble average value in panels c, $\mathrm{f}$ and i. For the CV1 and LT regions the WL and CM ensembles behave in the same way, both showing a delay in the onset of the event and an underestimation of the peak intensity. The simulated intensity is higher for the WL than the CM, consistently with what is observed in Fig. 2. For the CV2 region, both the WL and CM ensembles exhibit the same time delay and similar peak precipitation underestimations.

\subsubsection{Case 2}

Case 2 (called AUSTRIA hereafter) is a convective orographic precipitation event with weak but persistent largescale driving factors that was induced by the evolution of a shallow trough over the North Atlantic, from 22 to 25 June 2009. A cutoff low was isolated over Southern Europe, thus inducing persistent northeasterly flow over Austria, associated with unstable warm-moist air, impinging on the Alps. This caused extreme rainfall along the northern flanks of the Alps due to orographic lifting. On June 24, however, the position of the rainfall maximum moved further to the east and south (Burgenland and South-Eastern Styria) because of strong embedded deep-convective cells (Haiden 2009). On June 25 , the regionally extended event ended and became more localised and scattered. The overall largest 6-day (22-27 June) rainfall sum was recorded at station Steinholz (lower Austria, located in the northern foothills of the Eastern Alps) with $354 \mathrm{~mm}$ and a return period of more than 100 years (Godina and Müller 2009).

In Fig. 4 the same analysis as Fig. 2 is reported but for Case 2 precipitation. The observed precipitation (Fig. 4a) shows a hook-shaped spatial pattern with the highest maxima following the terrain elevation peaks and a secondary maximum in the southeastern part of the domain. The WL ensemble (Fig. 4b1) shows a less pronounced hook shape precipitation, with the first maximum well located but with lower intensity than observed and with the secondary maximum definitely underestimated. These translate in a percentage of $90 \%$ of the models that have a spatial correlation pattern of the total accumulated precipitation higher than 0.5 (see Table 4). The CM ensemble (Fig. 4b2) reduces even more this signal up to a $60 \%$ underestimation 
Table 3 Spatial correlation of the total accumulated precipitation between simulations and interpolated observation for each of the boxes identified in the Case 1

\begin{tabular}{|c|c|c|c|c|c|c|}
\hline Models & $\begin{array}{l}\text { Case 1-IOP16 } \\
\text { Red box (WL) }\end{array}$ & $\begin{array}{l}\text { CAse 1-IOP16 } \\
\text { Red box }(\mathrm{CM})\end{array}$ & $\begin{array}{l}\text { Case 1-IOP16 } \\
\text { Green box (WL) }\end{array}$ & $\begin{array}{l}\text { Case } 1 \text {-IOP16 } \\
\text { Green box (CM) }\end{array}$ & $\begin{array}{l}\text { Case 1-IOP16 } \\
\text { Blue box (WL) }\end{array}$ & $\begin{array}{l}\text { Case } 1-\mathrm{IOP} 16 \\
\text { Blue box }(\mathrm{CM})\end{array}$ \\
\hline Ensemble & 0.74 & 0.65 & 0.67 & 0.45 & 0.60 & 0.77 \\
\hline RegCM4-ICTP & 0.30 & -0.11 & 0.20 & 0.28 & -0.02 & -0.19 \\
\hline RegCM4-DHMZ & 0.62 & 0.64 & 0.43 & 0.15 & -0.05 & 0.22 \\
\hline RegCM4-CUNI & 0.07 & 0.53 & -0.03 & -0.14 & -0.53 & -0.24 \\
\hline CCLM-JLU & 0.50 & 0.50 & 0.41 & 0.52 & 0.48 & 0.57 \\
\hline CCLM-KIT & 0.29 & 0.22 & 0.24 & 0.28 & 0.27 & 0.36 \\
\hline WRF-UHOH & 0.38 & 0.23 & 0.35 & 0.11 & 0.20 & 0.61 \\
\hline WRF-AUTH-MC & 0.57 & 0.48 & 0.58 & 0.33 & 0.31 & 0.75 \\
\hline WRF-FZJ-IBG3 & 0.44 & 0.37 & 0.49 & 0.50 & 0.32 & 0.71 \\
\hline WRF-IPSL & 0.56 & 0.15 & 0.45 & 0.38 & 0.18 & 0.45 \\
\hline WRF-BCCR & 0.50 & 0.54 & 0.21 & 0.24 & 0.34 & 0.68 \\
\hline WRF-UNICAN & 0.45 & 0.15 & 0.49 & 0.23 & 0.66 & 0.68 \\
\hline WRF-IDL & 0.52 & 0.29 & 0.52 & -0.14 & 0.46 & 0.60 \\
\hline WRF-CICERO & 0.61 & 0.15 & 0.51 & -0.06 & 0.27 & 0.52 \\
\hline REMO-GERICS & 0.54 & 0.06 & 0.37 & -0.36 & 0.50 & 0.64 \\
\hline HCLIM-KNMI & 0.33 & 0.64 & 0.65 & 0.39 & 0.54 & 0.75 \\
\hline HCLIM-METNo & 0.56 & 0.26 & 0.51 & 0.45 & -0.25 & 0.29 \\
\hline HCLIM-SMHI & 0.66 & 0.18 & 0.51 & 0.37 & 0.25 & 0.69 \\
\hline AROME-CNRM & 0.71 & 0.58 & 0.49 & 0.56 & 0.65 & 0.71 \\
\hline MOLOCH-CNR & 0.44 & 0.48 & 0.23 & -0.20 & 0.09 & 0.17 \\
\hline COSMO-KIT & 0.57 & 0.38 & 0.33 & 0.49 & 0.30 & 0.45 \\
\hline COSMO-CMCC & 0.51 & 0.50 & 0.54 & 0.39 & 0.18 & 0.33 \\
\hline
\end{tabular}

All the correlations higher than 0.5 are highlighted in bold

of the maximum value. In contrast to the previous case study, the CM ensemble value is the result of a few CM members capturing the event and even overestimating it, a few showing different spatial pattern distributions from observed and half of the ensemble members not capturing or severely underestimating it as it is confirmed from the drop of the percentage of models with good correlation score to only $42 \%$ (see Table 4 ). Also in this case the skill in following the time evolution of the events is maximum during the peak of the precipitation and the evolution in time of the skill for both WL and CM mode (Fig. 5a) and is consistent with Table 4.

This large uncertainty is well depicted in Fig. 5b, where the hourly accumulated precipitation averaged over the rectangular box in Fig. 4a is reported as a function of time. The individual CM ensemble members go from nearly zero mm to over 1.5 times the observed accumulation, while the WL ensemble members are more narrowly grouped around the observed accumulation line. The difference in behaviour between the two ensembles is evident in Fig. 5c where the CM ensemble shows an underestimation around the $60 \%$ of the correspondent observed curve and in accordance with Fig. 4.

\subsubsection{Case 3}

Case 3 (called FOEHN hereafter) is a Foehn event that occurred on November 2014 Kramer et al. (2017). In this case the slow eastward evolution of a deep trough, associated with a mid-latitude cyclone over the North Atlantic induced persistent southerly flow over the Alps. Steady orographic precipitation occurred on the windward side of the Alps, with a consequent release of latent heat and drying of the air, that induced a Foehn effect on the leeward side of the mountains. The slow eastward evolution of the trough caused persistent precipitation over the Alps with daily precipitation locally exceeding several hundreds of $\mathrm{mm}$ and reaching maxima around $500 \mathrm{~mm}$. From Fig. 6a, b we can see that both the WL and CM ensembles agree well with observations. All the single members of the WL and CM have a similar behavior, the spatial correlation of the total accumulated precipitation is above $70 \%$ in both cases (see Table 5), the time evolution of the models skill is similar among the WL and CM and is always very high (above 0.5 for most of the event) as it is shown in Fig. 7a, the maximum intensity is reproduced and the hourly evolution of the event is well captured (Fig. 7a). The model 


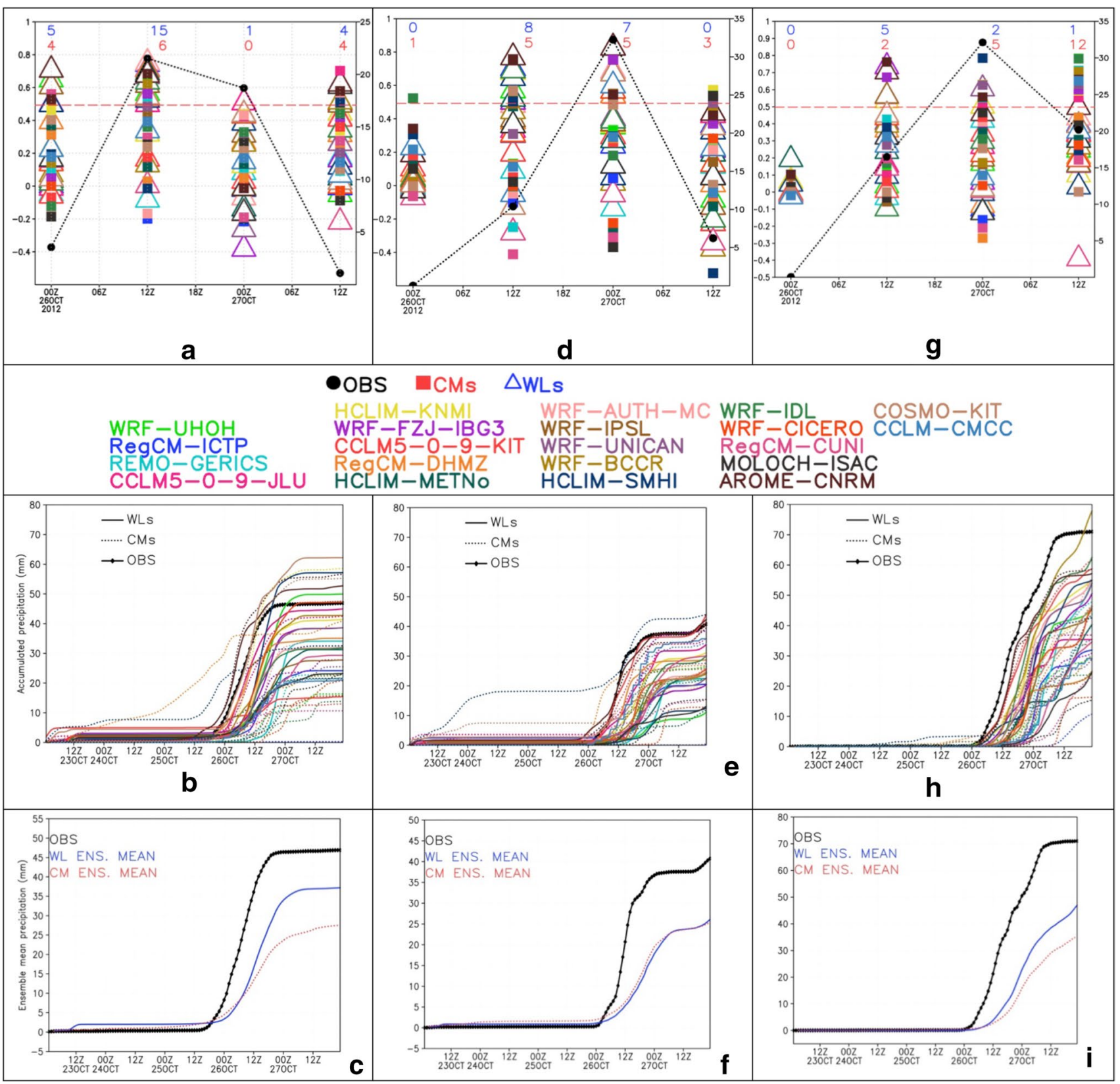

Fig. 3 Time series of the $12 \mathrm{~h}$ accumulated precipitation (in $\mathrm{mm}$ on the y-axis) during the event and temporal evolution of the spatial correlation between simulations and interpolated observation of the $12 \mathrm{~h}$ accumulated precipitation, over CV1, CV2 and LT boxes (panels a, d, g). Left hand side y-axes refer to correlation (colored symbols); right hand side $y$-axes refer to the accumulated precipitation (black line). Numbers of models with a correlation greater than 0.5 for WL simu- lation (in blue) and CM simulation (in red) are reported on the top of each plots. Time series of the hourly accumulated precipitation averaged over the red, green and blue boxes (Fig. 1a) for each model and observations (panels $\mathbf{b}$, e and $\mathbf{h}$ ). Time series of hourly accumulated precipitation ensemble mean (WL and CM respectively in blue and red) and observations (black) for the three areas of interest (panels c, f and i)

\section{Discussion}

In this manuscript we have introduced an ambitious, firstof-its-kind project that aims to design, produce and analyze multi-model ensembles of $\mathrm{CP}$ simulations. The project is 


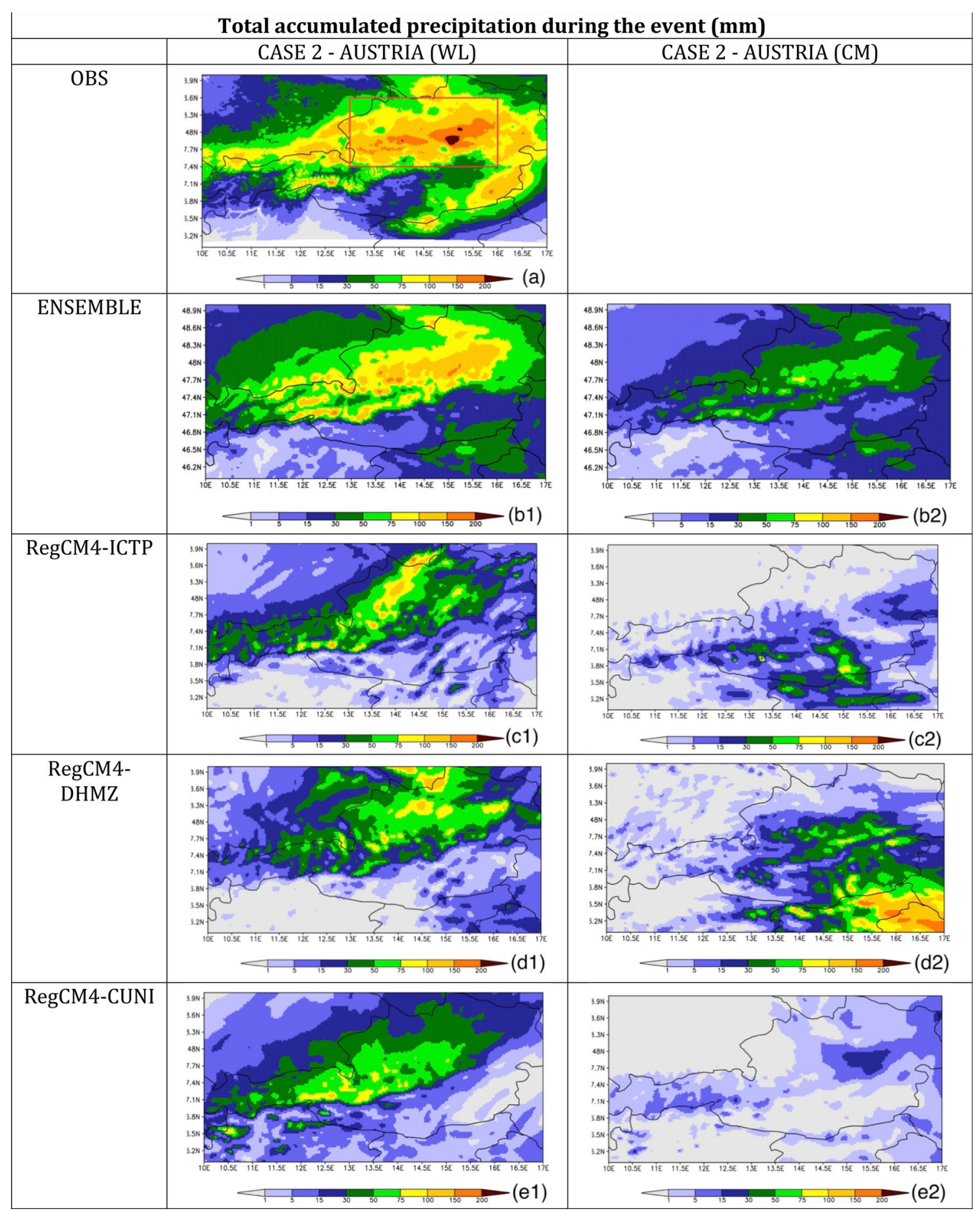

Fig. 4 Case 2-Austria. Total accumulated precipitation $(\mathrm{mm})$ for observations, multi-model ensemble mean and each ensemble member. Results are shown for the models run in WL mode (left) and in CM (right). Red box on panel a indicates specific area of interest

organized under the WCRP-sponsored CORDEX - Flagship Pilot Studies mechanism. As such, the project mobilizes participants from Euro-CORDEX, Med-CORDEX and CORDEX-ESD (Empirical Statistical Downscaling). The project has also engaged actors from outside the CORDEX community in order to bring in fresh perspectives and additional expertise. This diverse consortium is able to leverage years of expertise in NWP, climate modeling and downscaling, statistical modeling and downscaling. The overarching scientific aim of the project is to produce long-term simulations under present and future conditions at $\mathrm{CP}$ resolutions, with focus on increasing our understanding of convection, 


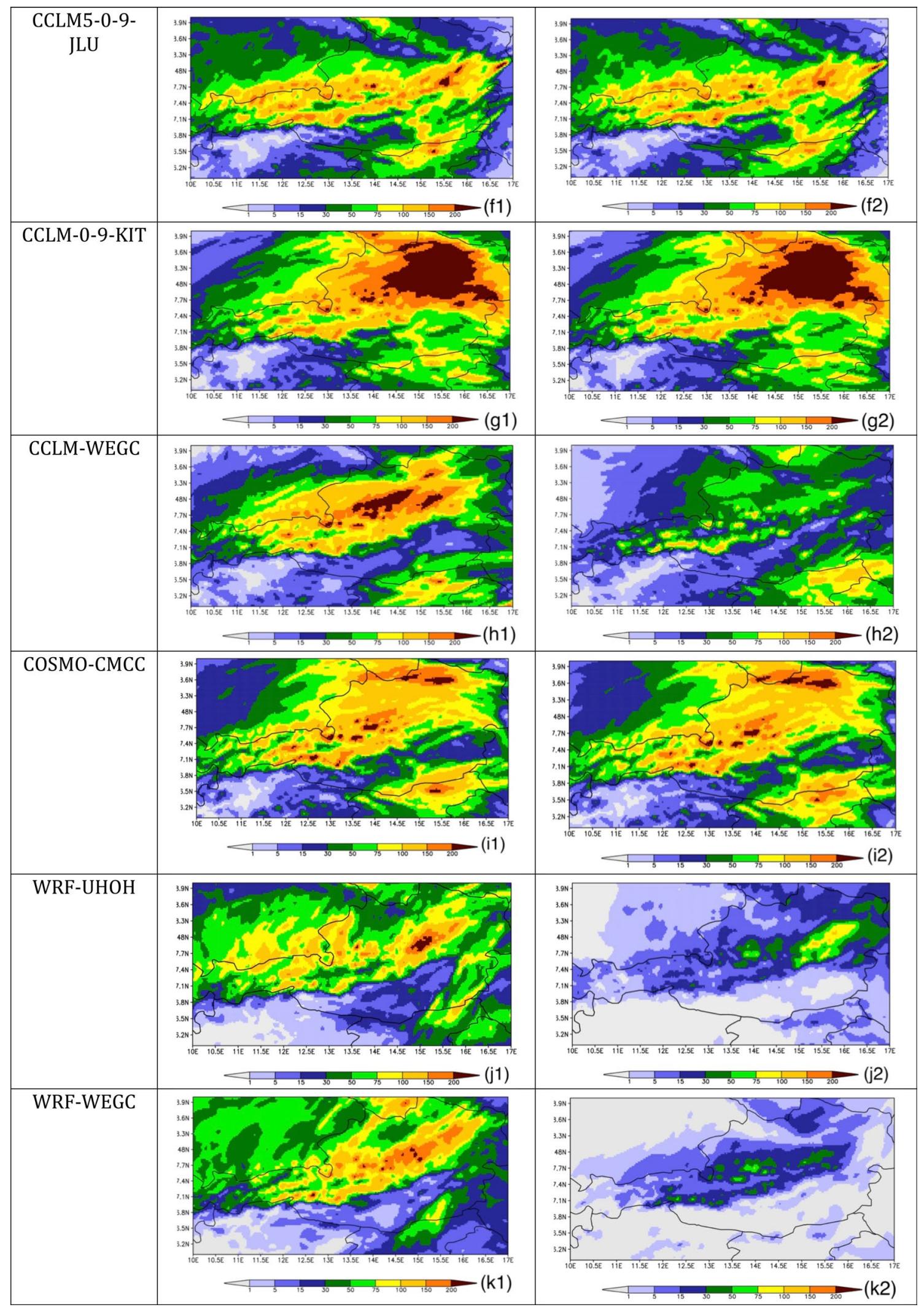

Fig. 4 (continued) 


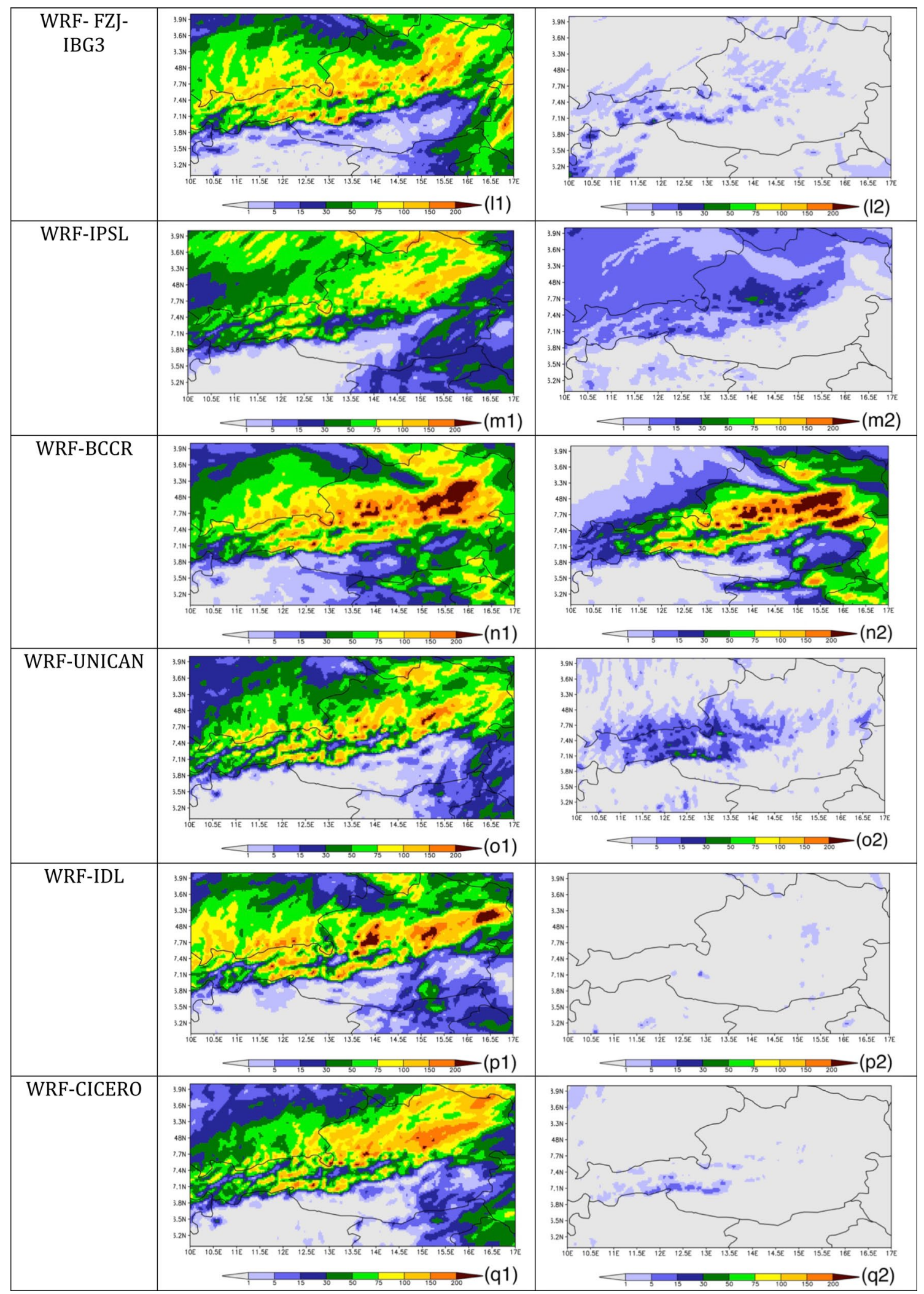

Fig. 4 (continued) 


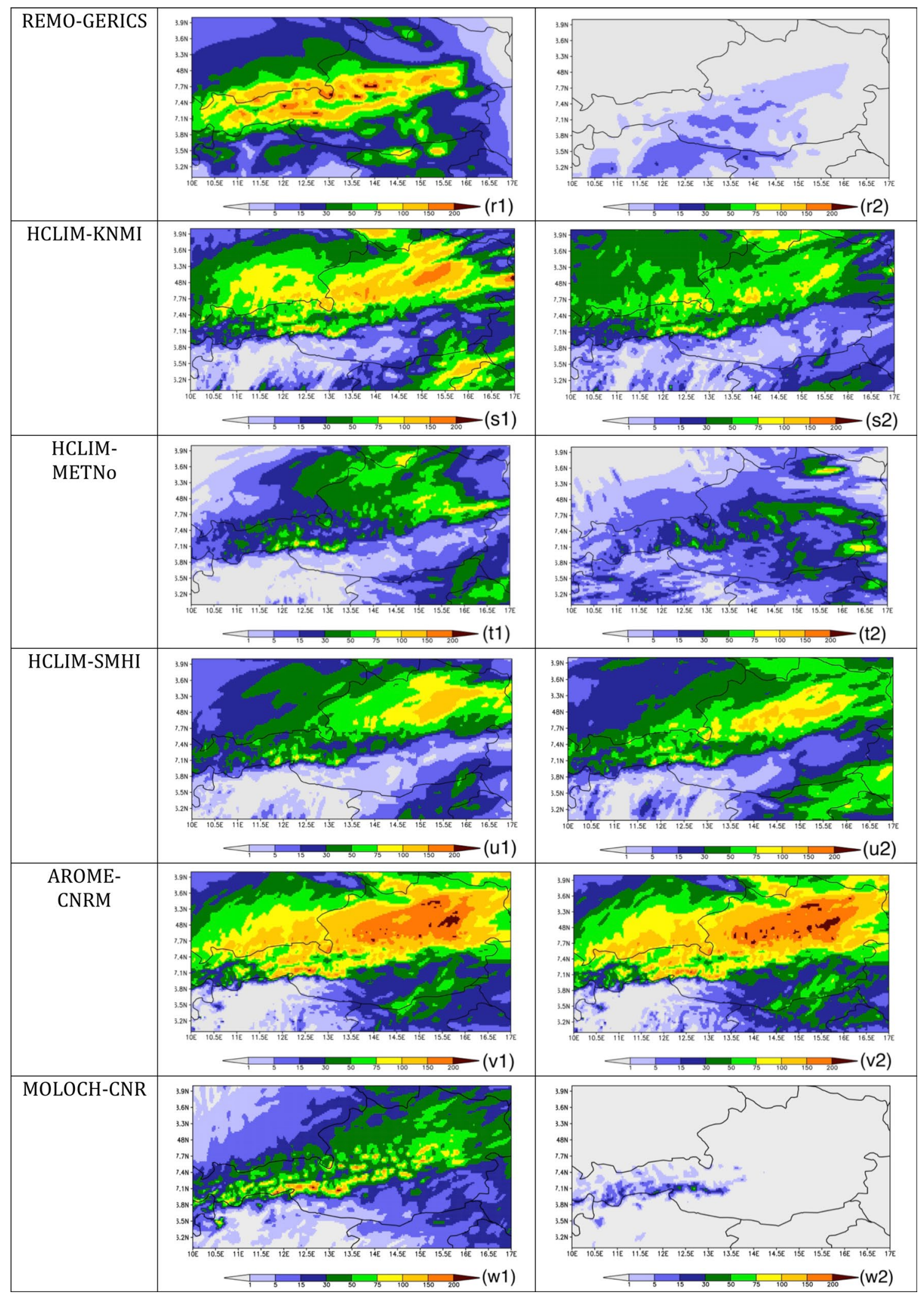

Fig. 4 (continued) 
Table 4 Same as Table 3 but for the Case 2

\begin{tabular}{lcc}
\hline Models & Case 2-Austria (WL) & $\begin{array}{l}\text { Case 2- } \\
\text { Austria } \\
(\mathrm{CM})\end{array}$ \\
\hline Ensemble & $\mathbf{0 . 8 2}$ & $\mathbf{0 . 8 1}$ \\
RegCM4-ICTP & $\mathbf{0 . 6 2}$ & -0.01 \\
RegCM4-DHMZ & $\mathbf{0 . 6 3}$ & 0.02 \\
RegCM4-CUNI & 0.49 & 0.37 \\
CCLM-JLU & $\mathbf{0 . 6 3}$ & $\mathbf{0 . 6 2}$ \\
CCLM-KIT & $\mathbf{0 . 7 7}$ & $\mathbf{0 . 7 7}$ \\
CCLM-WEGC & $\mathbf{0 . 7 5}$ & 0.39 \\
WRF-UHOH & $\mathbf{0 . 6 9}$ & $\mathbf{0 . 6 0}$ \\
WRF-WEGC & $\mathbf{0 . 6 8}$ & $\mathbf{0 . 6 1}$ \\
WRF-FZJ-IBG3 & $\mathbf{0 . 6 2}$ & 0.05 \\
WRF-IPSL & $\mathbf{0 . 5 4}$ & 0.47 \\
WRF-BCCR & $\mathbf{0 . 7 7}$ & $\mathbf{0 . 6 4}$ \\
WRF-UNICAN & $\mathbf{0 . 6 9}$ & 0.27 \\
WRF-IDL & $\mathbf{0 . 6 4}$ & 0.10 \\
WRF-CICERO & $\mathbf{0 . 6 7}$ & 0.05 \\
REMO-GERICS & 0.44 & 0.23 \\
HCLIM-KNMI & $\mathbf{0 . 6 7}$ & $\mathbf{0 . 6 0}$ \\
HCLIM-METNo & $\mathbf{0 . 6 2}$ & 0.41 \\
HCLIM-SMHI & $\mathbf{0 . 7 2}$ & $\mathbf{0 . 7 1}$ \\
AROME-CNRM & $\mathbf{0 . 8 3}$ & $\mathbf{0 . 8 2}$ \\
MOLOCH-CNR & $\mathbf{0 . 5 8}$ & $\mathbf{0 . 6 3}$ \\
COSMO-CMCC & $\mathbf{0 . 6 2}$ & \\
\hline & & $\mathbf{0 0}$ \\
& &
\end{tabular}

convective processes and their impacts in a global warming context. Given the challenges and costs involved in running dynamical models at CP-RCM scales, test cases were designed to provide a zero-order assessment of the ensemble and its characteristics. In this manuscript we have presented a preliminary and illustrative analysis of these case studies.

These preliminary results of the three case studies illustrate both the challenges and potential in CP-RCMs. They also provide a clear argument for the advantages of the ensemble-based approach. Case 1 is a fall HP event driven by the development of MCS over the western Mediterranean basin advecting moist air over three topographically complex regions in the southern coast of France and the Liguria-Tuscany regions. The three precipitation maxima are well located by both WL and CM ensembles. However, the intensity of the peaks is generally underestimated, especially in the CM experiments. Case 2 is an orographic precipitation event that shows the effects of internal variability more strongly in CM than the other cases. From the ensemble point of view the event is captured in both WL and CM mode, with the latter one showing much more damped signals. The Foehn case (Case 3) is characterized by persistent orographic precipitation driven by a slow eastward moving through and it was the best captured by the models. Both the
WL and CM ensembles were in very good agreement with observations, representing well both the timing and intensity of the HP event.

There are interesting and subtle differences between the case studies themselves and the ways in which the individual models represent them. Even within an individual test case there are differences in dominant processes that are then reflected by the ensemble. The general increase in spread (both spatially and temporally) between the WL and CM can be expected and points toward the strong effect of internally generated variability in the models.

Case 1 shows a larger spread over regions in which the precipitation is most affected by complex topography. Unsurprisingly, the individual WL and CM ensemble members exhibit a broader range of behaviors over these areas (the red and blue boxes in Fig. 2), which results in different ensemble mean responses. Conversely, the model behaviour is more consistent between WL and CM over the CV2 region (green box), resulting in very similar ensemble mean responses and correlation skill score of the individual models (Table 3; Fig. 3d). The heavy precipitation event over this area was the result of an organized MCS forming over the sea, weakly supported by the orographic forcing. In this case the WL simulations are closer to the CM behaviour on average (low predictability problem), with some members showing results as uncertain as in $\mathrm{CM}$.

Case 2 is in many ways the most interesting, with a wide range of model behaviours in the CM simulations. Some simulations completely miss the event while others exhibit a considerably damped response. Only 9 of the $21 \mathrm{CM}$ simulations have a total accumulated rainfall spatial pattern correlation with observations greater than 0.5 (Table 4). While one should not expect exact reproduction of events in terms of timing, location and intensity in CM, it is reasonable to expect credible representation of the events given the experiment design. Therefore we provide some discussion on why some models reproduced the salient characteristics of the event over Austria whereas some missed it entirely. A detailed investigation is beyond the scope of this paper, but we speculate that at least three factors may be responsible for this result. The first is that the event is close to the domain boundaries, which can be problematic, and model teams used varying sponge layer depths and nesting strategies. This last point is illustrated by the fact that the simulations that missed the event in its entirety all had an freely evolving (i.e. not nudged) intermediate nest, which allows internal variability to develop. Interestingly, the differences in nesting strategy did not have such a strong effect on the other test cases. Another factor is that this event occurred in a relatively weak background synoptic state, which would decrease the large scale forcing compared to the local forcing, and thus increase diversity across models. Lastly, though the spread 


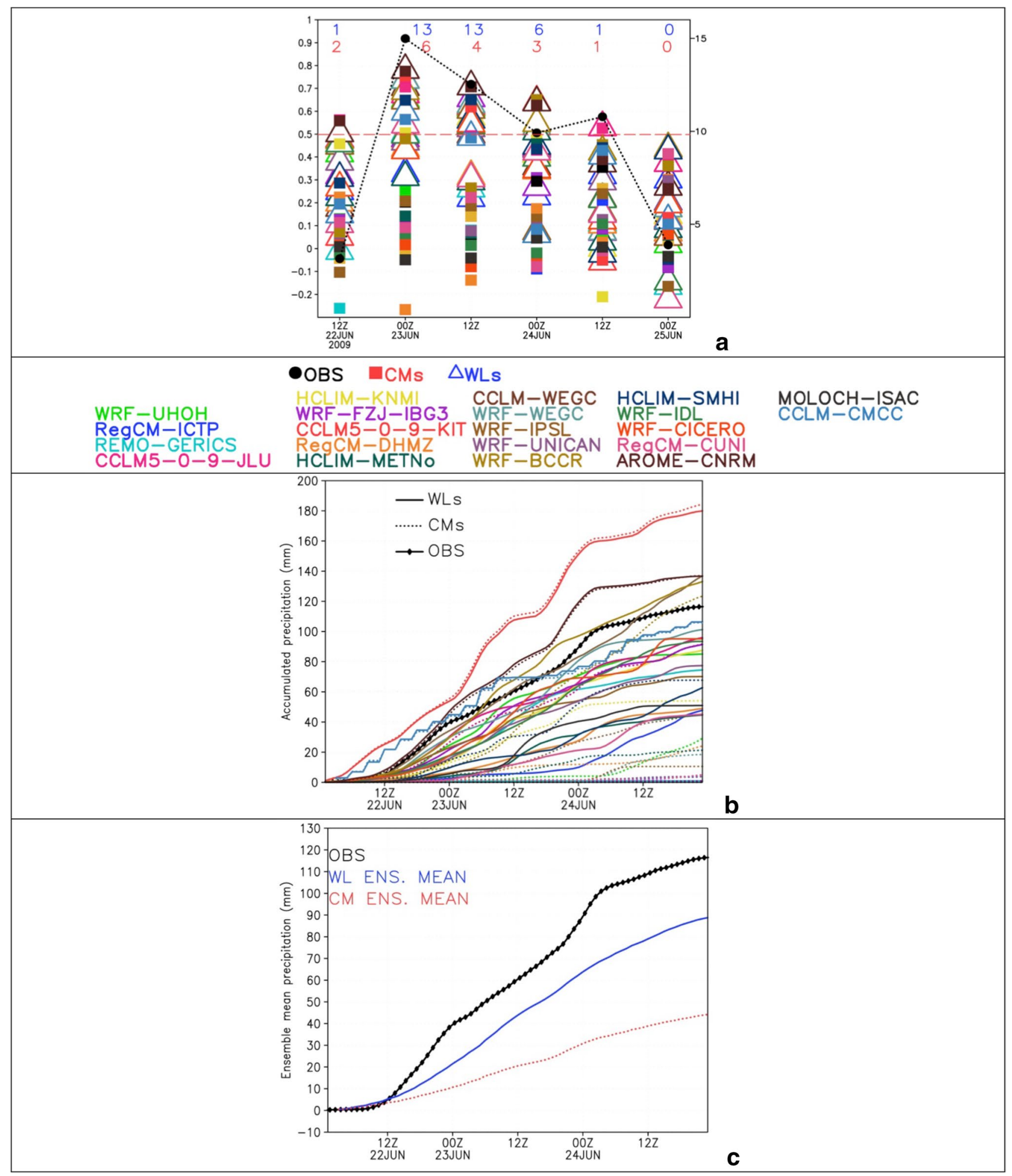

Fig. 5 Time series of the $12 \mathrm{~h}$ accumulated precipitation (in $\mathrm{mm}$ on the $y$ axis) during the event and temporal evolution of the spatial correlation of the accumulated $12 \mathrm{~h}$ precipitation between the simulations and observation (a). Left hand side y axes refer to correlation (colored symbols); right hand side y-axes refer to the accumulated precipitation (black line). Numbers of models with a correlation greater than 0.5 for WL simulation (in blue) and CM simulation (in red). Time series of the precipitation averaged over the red area (Fig. 3a) for each model and observations (b). Time series of hourly accumulated precipitation ensemble mean(WL and CM respectively in blue and red) and observations (black) over the area of interest (c) 


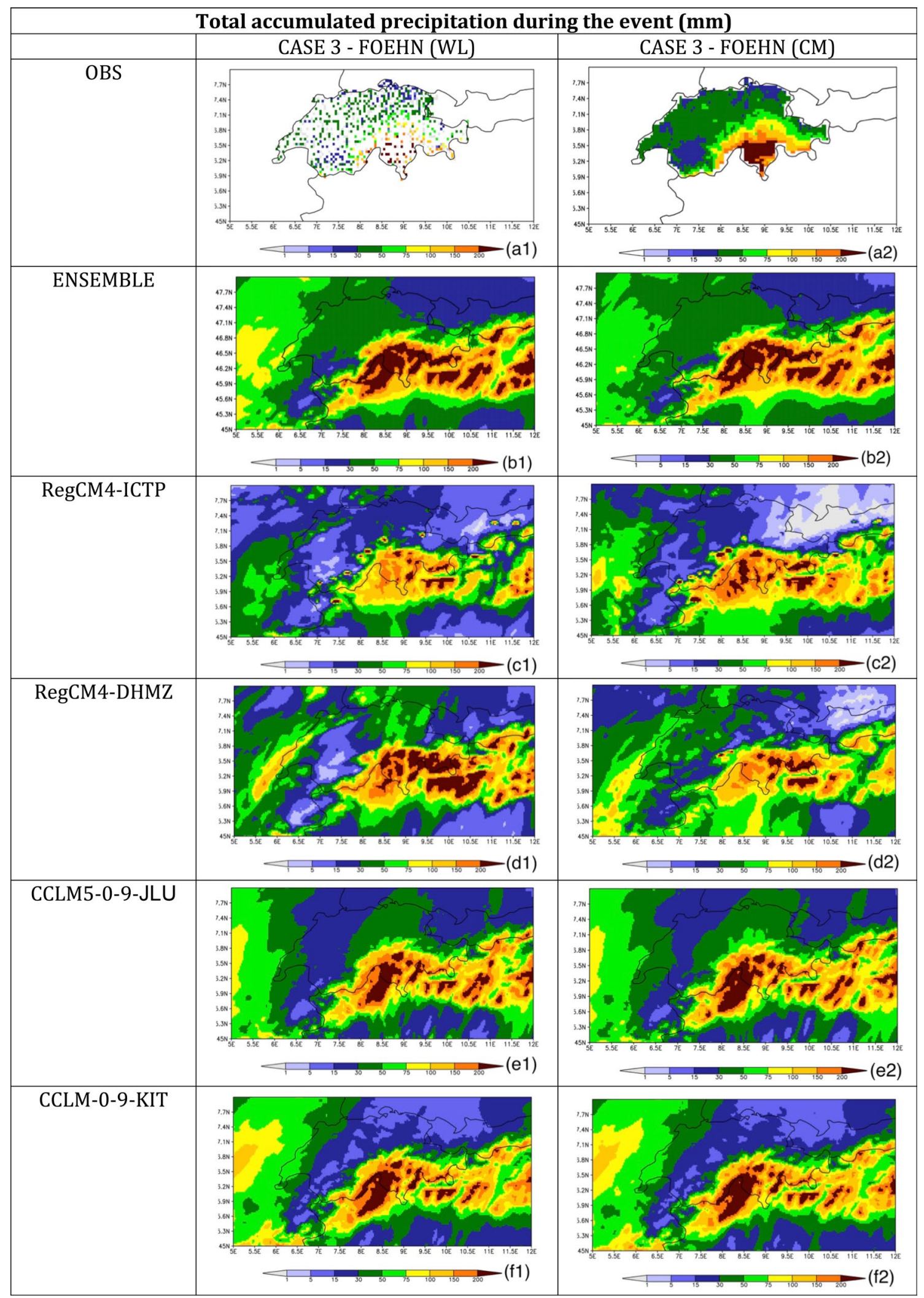

Fig. 6 Case 3-FOEHN. Total accumulated precipitation $(\mathrm{mm})$ for observations, multi-model ensemble mean and each ensemble member. Results are shown for the models run in WL mode (left) and in CM (right). a2 Shows an interpolation of the observed precipitation field 


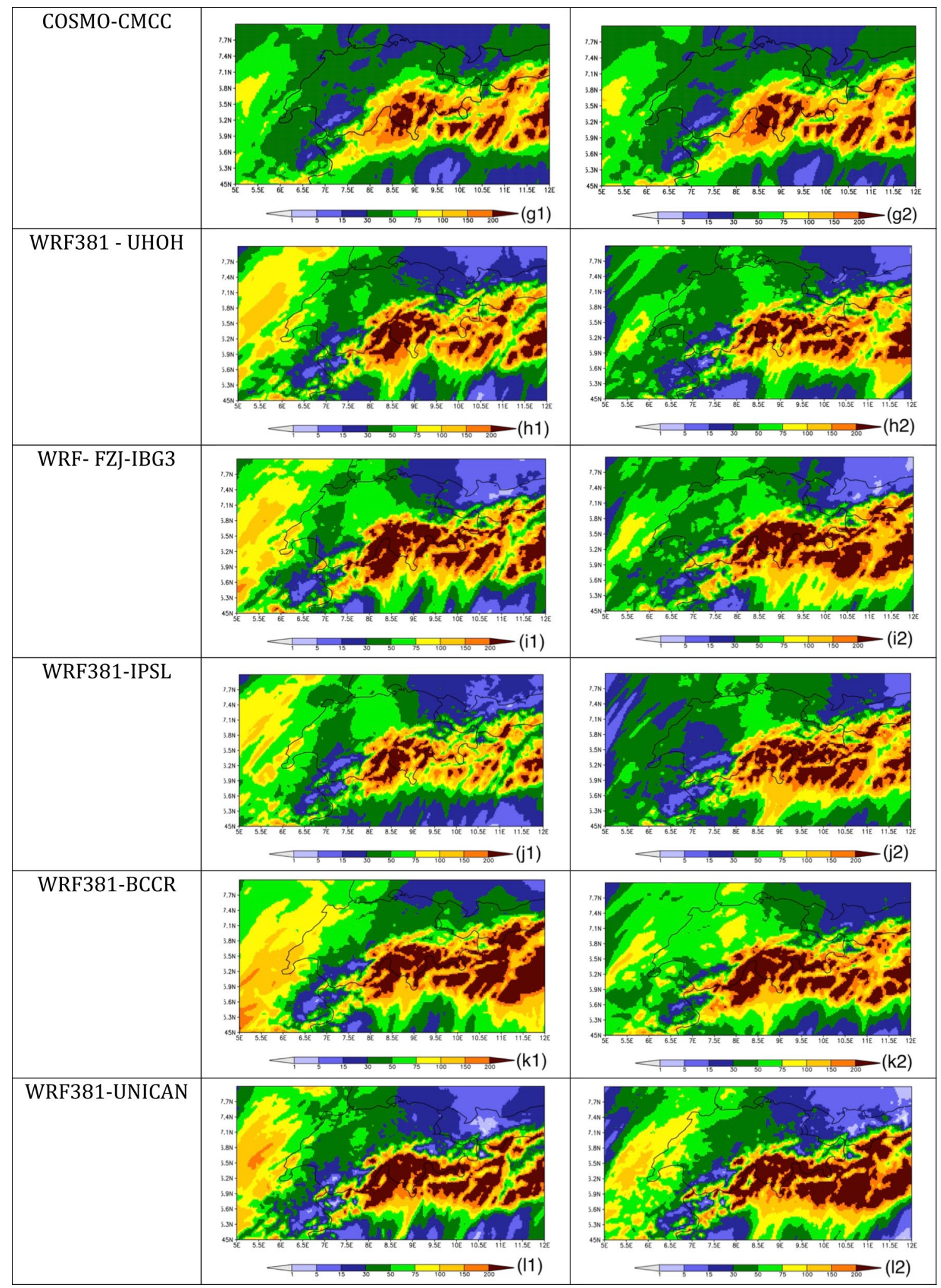

Fig. 6 (continued) 


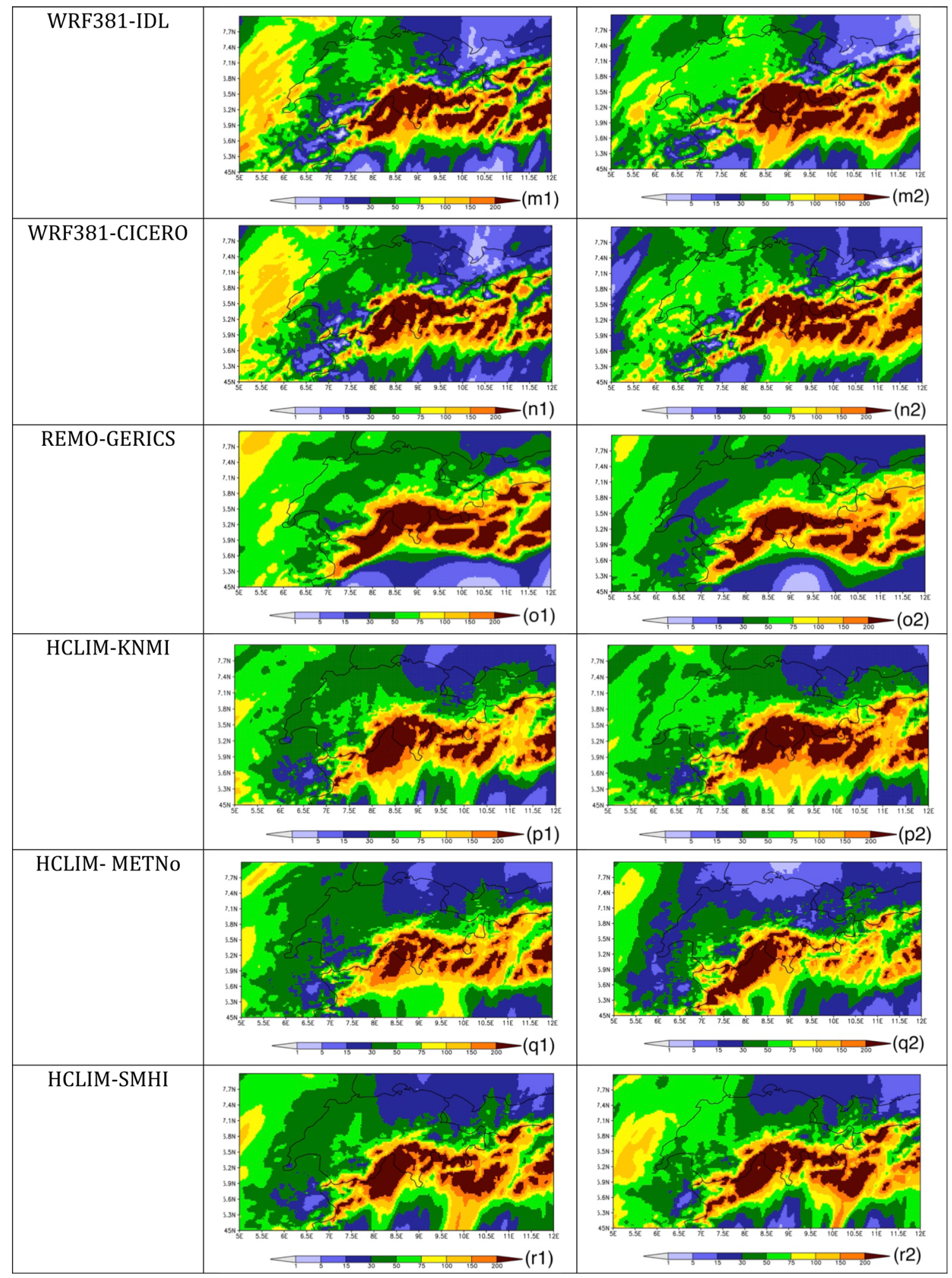

Fig. 6 (continued)

is large, the ensemble mean pattern captures the event, and the location of each simulations' maximum rainfall is roughly in the correct region (i.e. along the Northern foothills of the Austrian Alps, not shown). This can be considered as a good starting point for a future analysis where a more in depth investigation will be needed to fully 


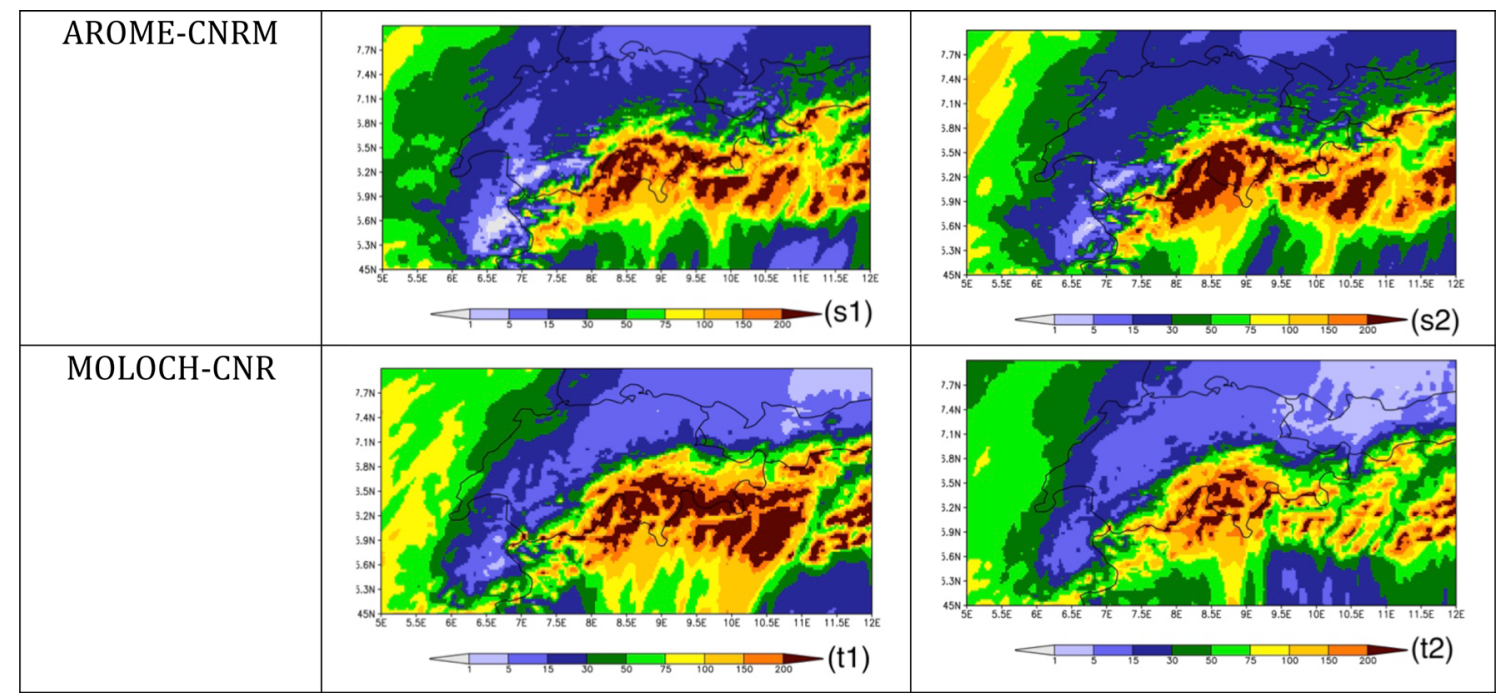

Fig. 6 (continued)

Table 5 Same as Table 3 but for the Case 3

\begin{tabular}{lll}
\hline Models & Case 3-FOEHN (WL) & $\begin{array}{l}\text { Case 3- } \\
\text { FOEHN } \\
(\mathrm{CM})\end{array}$ \\
\hline Ensemble & 0.91 & 0.90 \\
RegCM4-ICTP & 0.78 & 0.73 \\
RegCM4-DHMZ & 0.78 & 0.77 \\
CCLM-JLU & 0.92 & 0.89 \\
CCLM-KIT & 0.87 & 0.86 \\
WRF-UHOH & 0.86 & 0.84 \\
WRF-FZJ-IBG3 & 0.78 & 0.81 \\
WRF-IPSL & 0.84 & 0.81 \\
WRF-BCCR & 0.82 & 0.85 \\
WRF-UNICAN & 0.86 & 0.82 \\
WRF-IDL & 0.84 & 0.84 \\
WRF-CICERO & 0.85 & 0.82 \\
REMO-GERICS & 0.91 & 0.90 \\
HCLIM-KNMI & 0.89 & 0.90 \\
HCLIM-METNo & 0.90 & 0.83 \\
HCLIM-SMHI & 0.87 & 0.87 \\
AROME-CNRM & 0.89 & 0.91 \\
MOLOCH-CNR & 0.86 & 0.89 \\
COSMO-CMCC & 0.90 & 0.90 \\
\hline
\end{tabular}

understand the driver of the HP event and the reason some of the models do not capture it.

Case 3 showed the best model performance in both the WL and CM ensembles. In this experiment, both the ensemble mean and all individual members reproduce the results, in terms of precipitation, of a strong Foehn event. The reason for this could be that this event is driven by a well-defined, slowly-evolving large-scale circulation which forced longlasting orographic precipitation over the Alps. It is worth mentioning that this case presents the typical synoptic conditions conducive to heavy Alpine rainfall, which are easier to predict than average conditions (Grazzini 2007). Therefore, models which are able to capture the large scale organization of the precipitating system can provide a quite surprising reproduction of the event, provided that convective precipitation, embedded in the stratiform rainfall, is represented.

The preliminary results presented here have important implications for the longer term simulations the project aims to undertake, and more generally for the use of CPRCM in a climate context; one is that results can be highly model and event dependent. They suggest that we can expect varying ranges of responses for different types of convective events (e.g. strongly steered by synoptic conditions vs. weakly steered, local scale interactions with complex topography vs. stronger ocean influence, etc.), which would affect uncertainties in future projections. As Grell et al. (2000) noted, precipitation over complex terrain is not likely to converge toward one solution at CP-RCM scales and, more importantly, the precipitation moves with the local upper level flow unlike in coarser RCM simulations where the precipitation remains locked to the mountain tops. For test cases, however, it is difficult to disentangle the extent to which model differences are due to internal noise (which will lead to differences in the timing, positioning and evolution of specific event, particularly if not strongly forced by the large-scale conditions) or due to differences in model physics. Multi-year climatological statistics will be less influenced by internal noise and hence the intercomparison of results from the upcoming ERA-Interim (and scenario) simulation across 


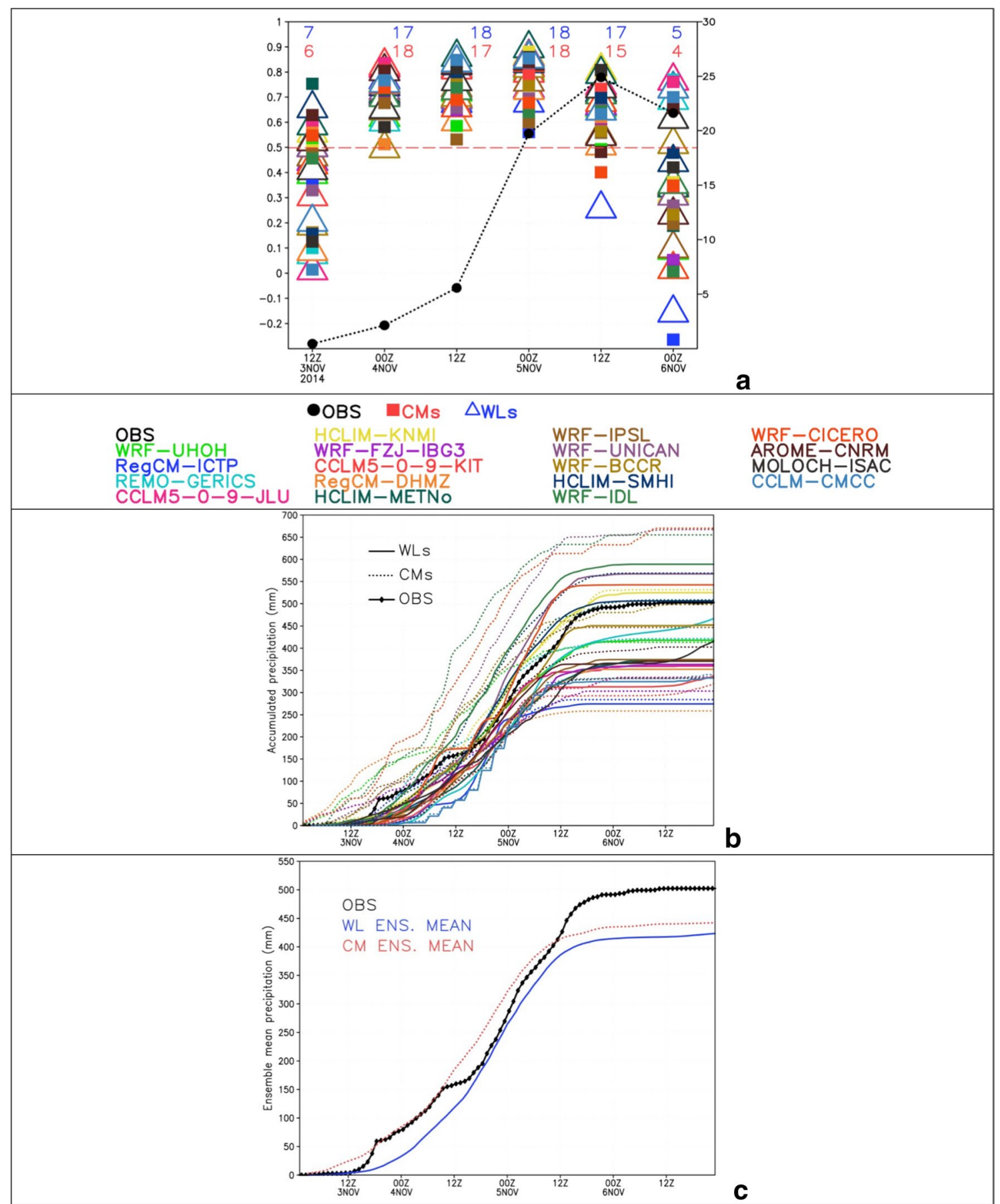

Fig. 7 Time series of the $12 \mathrm{~h}$ accumulated precipitation (in $\mathrm{mm}$ on the y-axis) during the event and temporal evolution of the spatial correlation of the accumulated $12 \mathrm{~h}$ precipitation between the simulations and observation (a). Left hand side y axes refer to correlation (colored symbols); right hand side y-axes refer to the accumulated precipitation (black line). Numbers of models with a correlation

models will allow a more in depth understanding of model performance and uncertainty. For more insight on some of the issues raised here, the authors would like to point the greater than 0.5 for WL simulation (in blue) and CM simulation (in red). Time series of the precipitation over the point of maximum accumulation for each model and observations (b). Time series of hourly accumulated precipitation ensemble mean (WL and CM respectively in blue and red) and observations (black) over the observation area $(\mathbf{c})$

reader to the other papers in the special collection convection permitting modeling.

The CORDEX-FPS on convection over Europe and the Mediterranean is an ambitious and challenging undertaking. 
It has a tremendous potential and is a logical next step to bring together the Euro-CORDEX, Med-CORDEX and the nascent scientific communities forming around the use of $\mathrm{CP}-\mathrm{RCM}$ on climate scales. The findings from the project will enhance our understanding of convective processes and their response to climate warming, which may bring some surprises with respect to the findings from coarse resolution models (e.g. Giorgi et al. 2016). Further, as recent single model, longer-term climate change CP-RCM experiments indicate, previously unresolved but highly destructive features such as intense mesoscale convective systems increase substantially in a warming climate (Prein et al. 2017). The project will, therefore, also provide critical added value to decision makers as ensemble-based and combined dynamical-statistical approaches will help improve confidence even under conditions of high uncertainty. The initiative is open to all interested scientists and potential collaborators are encouraged to contact the project leaders if they wish to participate.

Acknowledgements IG and LS have been supported by the Croatian Science Foundation (HrZZ) project CARE (no. 2831). JF acknowledges support by the Spanish $\mathrm{R}+\mathrm{D}$ programme through MINECO/ FEDER co-funded project INSIGNIA (CGL2016-79210-R). AL-G is supported by the Spanish government though grant BES-2016-078158 and MINECO/FEDER co-funded project MULTI-SDM (CGL201566583-R). UCAN simulations have been carried out on the Altamira Supercomputer at the Instituto de Física de Cantabria (IFCA, CSICUC), member of the Spanish Supercomputing Network. Computational resources were partly made available by the German Climate Computing Center (DKRZ) through support from the BMBF. JM and KW-S gratefully acknowledge the support by the German Science Foundation (DFG) through project FOR 1695. UHOH simulations were carried out at the supercomputing center HLRS in Stuttgart, Germany. DM, MP, and HT gratefully acknowledge the support received via the Austrian Science Fund (FWF) project NHCM-2 (no. P24758-N29) and the projects HighEnd:Extremes and EASICLIM, funded by the Austrian Climate Research Programme (ACRP) of the Klima- und Energiefonds (nos. KR13AC6K10981 and KR16AC0K13160, respectively). DM, MP and HT are also thankful for the computational resources received the Vienna Scientific Cluster (VSC). KG, SK, HT and MP gratefully acknowledge the computing time granted by the John von Neumann Institute for Computing (NIC) and provided on the supercomputer JURECA at Jülich Supercomputing Centre (JSC) through grant hka19. DH gratefully acknowledges the Gauss Centre for Supercomputing e.V. (http://www.gauss-centre.eu) for funding this project by providing computing time on the GCS Supercomputer JUQUEEN at Jülich Supercomputing Centre (JSC) through grant hka19. SS and TL acknowledge the support of NOTUR project no. NN9280K and the Research Council of Norway and its basic institute support of their strategic project on Climate Services. The authors gratefully acknowledge the Austrian Central Department for Meteorology and Geodynamics (ZAMG) for providing analysis fields of the Integrated Nowcasting through Comprehensive Analysis (INCA) system. IPSL's work was granted access to the HPC resources of TGCC under the allocations 2017-A0010106313 and 2017-A0030106877 made by GENCI. RMC and PMMS gratefully acknowledge the support of the SOLAR project (PTDC/GEOMET/7078/2014) financed by the Portuguese Foundation for Science and Technology. QF and SS acknowledge the support of the Meteo-France computing center and warmly thank Antoinette Alias and Michel Déqué for their contributions. EJ Kendon gratefully acknowledges funding from the Joint Department of Energy and Climate Change (DECC) and Department for Environment Food and Rural Affairs (Defra) Met Office Hadley Centre Climate Programme (GA01101). S. Khodayar research is supported by the Bundesministerium für Bildung und Forschung (BMBF; German Federal Ministry of Education and Research). EK and SK acknowledge the support of the Greek Research and Technology Network (GRNET) High Performance Computing (HPC) infrastructure for providing the computational resources of AUTH-simulations and the AUTH Scientific Computing Center for technical support. TH and MB (CUNI) acknowledge the support of the IT4Innovations-National Supercomputer Centre of the Czech Republic providing the computational resources for the CUNI simulations and the support of Ministry of Education, Youth and Sports of the Czech Republic for funding the participation in EuroCORDEX activities via the scheme INTER-TRANSFER under the Grant no. LTT17007. LM, GM and ØH acknowledge supercomputer facilities provided by NOTUR, and funding from the Research Council of Norway through the SUPER (Grant no. 250573) and HYPRE (Grant no. 243942) projects. HCLIM-KNMI simulations were supported by ECMWF (computing time through special project SPNLSTER) and the Dutch Ministry of Infrastructure and the Environment. HdV and EvM like to thank Bert van Ulft from KNMI for carrying out the Harmonie simulations. ICTP thanks the CINECA super computer center for the HPC facilities used for those simulations. The authors also wish to thank MeteoGroup Switzerland for providing observational data for the Foehn test case, Meteo-France and the HyMeX program (sponsored by Grants MISTRALS/HyMeX and ANR-11-BS56-0005 IODA-MED project) for supplying the data for HyMeX-IOP16 case, the Wegener Center (especially Jürgen Fuchsberger) for providing WegenerNet data for the Austria case.

\section{References}

Argüeso D, Evans JP, Fita L, Bormann KJ (2014) Temperature response to future urbanization and climate change. Clim Dyn 42(7-8):2183-2199

Ban N, Schmidli J, Schär C (2014) Evaluation of the convectionresolving regional climate modeling approach in decade-long simulations. J Geophys Res Atmos 119:7889-7907. https://doi. org/10.1002/2014JD021478

Ban N, Schmidli J, Schär C (2015) Heavy precipitation in a changing climate: Does short-term summer precipitation increase faster? Geophys Res Lett 42:1165-1172. https://doi.org/10.1002/2014G L062588

Beaulant A-L, Joly B, Nuissier O, Somot S, Ducrocq V, Joly A, Sevault F, Deque M, Ricard D (2011) Statistico-dynamical downscaling for Mediterranean heavy precipitation. Q J R Meteorol Soc 137:736-748

Beniston M (2006) August 2005 intense rainfall event in Switzerland: Not necessarily an analog for strong convective events in a greenhouse climate. Geophys Res Lett 33(5):L05701. https://doi. org/10.1029/2005GL025573

Benoit R, Schär C, Binder P, Chamberland S, Davies HC, Desgagné M, Girard C, Keil C, Kouwen N, Lüthi D, Maric D, Müller E, Pellerin P, Schmidli J, Schubiger F, Schwierz C, Sprenger M, Walser A, Willemse S, Yu W, Zala E (2002) The real-time ultra finescale forecast support during the special observing period of the MAP. Bull Amer Meteor Soc 83:85-109

Bony S, Stevens B, Frierson DM, Jakob C, Kageyama M, Pincus R, Shepherd TG, Sherwood SC, Siebesma AP, Sobel AH, Watanabe M (2015) Clouds, circulation and climate sensitivity. Nat Geosci 8(4):261-268 
Brisson E, Van Weverberg K, Demuzere M, Devis A, Saeed S, Stengel M, van Lipzig NP (2016) How well can a convectionpermitting climate model reproduce decadal statistics of precipitation, temperature and cloud characteristics? Clim Dyn 47(9-10):3043-3061

Carvalho LM, Jones C, Liebmann B (2002) Extreme precipitation events in southeastern South America and large-scale convective patterns in the South Atlantic convergence zone. J Clim 15(17):2377-2394

Chen SS et al (2016) Aircraft observations of dry air, the ITCZ, convective cloud systems, and cold pools in MJO during DYNAMO. Bull Am Meteorol Soc 97:405-423. https://doi. org/10.1175/BAMS-D-13-00196.1

Davis C, Brown B, Bullock R (2006) Object-based verification of precipitation forecasts: part II. Application to convective rain systems. Mon Weather Rev 134(7):1785-1795. https://doi. org/10.1175/MWR3146.1

Dee DP, Uppala SM, Simmons AJ, Berrisford P, Poli P, Kobayashi S, Bechtold P et al (2011) The ERA-Interim reanalysis: configuration and performance of the data assimilation system. Q J R Meteorol Soc 137(656):553-597

Delrieu G, Wijbrans A, Boudevillain B, Faure D, Bonnifait L, Kirstetter PE (2014) Geostatistical radar-raingauge merging: a novel method for the quantification of rain estimation accuracy. Adv Water Resour 71:110-124

Déqué M, Alias A, Somot S, Nuissier O (2016) Climate change and extreme precipitation: the response by a convection-resolving model. Research activities in atmospheric and oceanic modelling. CAS/JSC Working group on numerical experimentation. Report No. 46. http://www.wcrp-climate.org/WGNE/blue_book. html. Accessed 5 Dec 2017

Deser C, Phillips A, Bourdette V, Teng H (2012) Uncertainty in climate change projections: the role of internal variability. Clim Dyn 38(3-4):527-546

Deser C, Phillips AS, Alexander MA, Smoliak BV (2014) Projecting North American climate over the next 50 years: Uncertainty due to internal variability. J Clim 27(6):2271-2296

Dirmeyer PA, Cash BA, Kinter JL, Jung T, Marx L, Satoh M, Stan C, Tomita H, Towers P, Wedi N, Achuthavarier D (2012) Simulating the diurnal cycle of rainfall in global climate models: Resolution versus parameterization. Clim Dyn 39(1-2):399-418

Done J, Davis CA, Weisman M (2004) The next generation of NWP: Explicit forecasts of convection using the Weather Research And Forecasting (WRF) model. Atmos Sci Lett 5(6):10-117

Ducrocq V, Ricard D, Lafore JP, Orain F (2002) Storm-scale numerical rainfall prediction for five precipitating events over France: on the importance of the initial humidity field. Weather Forecast $17: 1236-1256$

Ducrocq V, Nuissier O, Ricard D, Lebeaupin C, Thouvenin T (2008) A numerical study of three catastrophic precipitating events over southern france. ii: Mesoscale triggering and stationarity factors. Q J R Meteorol Soc 134(630):131-145

Ducrocq V, Braud I, Davolio S, Ferretti R, Flamant C, Jansa A, Kalthoff N, Richard E, Taupier-Letage I, Ayral PA, Belamari S, Berne A, Borga M, Boudevillain B, Bock O, Boichard JL, Bouin MN, Bousquet O, Bouvier C, Chiggiato J, Cimini D, Corsmeier U, Coppola L, Cocquerez P, Defer E, Drobinski P, Dufournet Y, Fourrie N, Gourley JJ, Labatut L, Lambert D, Le Coz J, Marzano FS, Molinie G, Montani A, Nord G, Nuret M, Ramage K, Rison B, Roussot O, Said F, Schwarzenboeck A, Testor P, Van Baelen J, Vincendon B, Aran M (2014) HyMeX-SOP1: the field campaign dedicated to heavy precipitation and flash flooding in the northwestern Mediterranean. Bull Am Meteor Soc 95(7): 1083-1100

Duffourg F, Nuissier O, Ducrocq V, Flamant C, Chazette P, Delanoë J, Doerenbecher A, Fourrié N, Di Girolamo P, Lac C et al (2016)
Offshore deep convection initiation and maintenance during the hymex iop 16a heavy precipitation event. Q J R Meteorol Soc 142(S1):259-274

Fosser G, Khodayar S, Berg P (2014) Benefit of convection permitting climate model simulations in the representation of convective precipitation. Clim Dyn 44(1-2):45-60

Giorgi F, Jones C, Asrar GR (2009) Addressing climate information needs at the regional level: the CORDEX framework. WMO Bull 58(3): $175-183$

Giorgi F,C, Torma E, Coppola N, Ban C, Schar, Somot S (2016) Enhanced summer convective rainfall at Alpine high elevations in response to climate warming. Nat Geosci 9:584-589

Godina R, Müller G (2009) Das Hochwasser in Österreich vom 22. bis 30 Juni, 2009-Beschreibung der hydrologischen Situation (in German), Report, pp 21, Austrian Federal Ministry of Agriculture, Forestry, Environment and Water Management (BMLFUW), Abt. VII/3., Vienna, Austria. https://www.bmlfuw.gv.at/wasser/ wasser-oesterreich/wasserkreislauf/hydrograph_charakt_extrema/ Hochwasser-Juni2009.html. Accessed 5 Dec 2017

Grazzini F (2007) Predictability of a large-scale flow conducive to extreme precipitation over the western Alps. Met Atm Phys 95:123-138

Grell GA, Schade L, Knoche R, Pfeiffer A, Egger J (2000) Nonhydrostatic climate simulations of precipitation over complex terrain. J Geophys Res 105(D24):29595-29608

Gutowski WJ Jr, Giorgi F, Timbal B, Frigon A, Jacob D, Kang HS, Raghavan K, Lee B, Lennard C, Nikulin G, O'Rourke E, Rixen M, Solman S, Stephenson T, Tangang F (2016) WCRP coordinated regional downscaling experiment (CORDEX): a diagnostic MIP for CMIP6. Geosci Model Dev 9:4087-4095. https://doi. org/10.5194/gmd-9-4087-2016

Haiden, Pistotnik G (2009) Intensity-dependent parameterization of elevation effects in precipitation analysis. Adv Geosci 20:33-38

Hawkins E, Sutton R (2009) The potential to narrow uncertainty in regional climate predictions. Bull Am Meteor Soc 90(8):1095-1107

Heinzeller D, Junkermann W, Kunstmann H (2016) Anthropogenic aerosol emissions and rainfall decline in Southwestern Australia: coincidence or causality? J Clim 29:8471-8493. https://doi. org/10.1175/JCLI-D-16-0082.1

Hohenegger C, Brockhaus P, Bretherton CS, Schär C (2009) The soil moisture-precipitation feedback in simulations with explicit and parameterized convection. J Clim 22(19):5003-5020

Holloway CE, Neelin JD (2009) Moisture vertical structure, column water vapor, and tropical deep convection. J Atmos Sci 66:1665-1683

Jakob M, Weatherly H (2003) A hydroclimatic threshold for landslide initiation on the North Shore Mountains of Vancouver, British Columbia. Geomorphology 54(3):137-156

Kendon EJ, Roberts NN, Senior CA, Roberts MJ (2012) Realism of rainfall in a very high-resolution regional climate model. J Clim 25:5791-5806. https://doi.org/10.1175/JCLI-D-11-00562.1

Kendon EJ, Roberts NM, Fowler HJ, Roberts MJ, Chan SC, Senior CA (2014) Heavier summer downpours with climate change revealed by weather forecast resolution model. Nat Clim Change 4(7):570-576

Khairoutdinov MF, Randall D (2006) High-resolution simulation of shallow to deep convection transition over land. J Atmos Sci 63:3421-3436

Khodayar S, Fosser G, Segolene B, Davolio S, Drobinski P, Ducrocq V, Ferretti R, Nuret M, Pichelli E, Richard E (2016) A seamless weather-climate multi-model intercomparison on the representation of high impact weather in the Western Mediterranean: HyMeX IOP12. Q J R Meteorol Soc 142:433-452. https://doi. org/10.1002/qj.2700 
Klein SA, Zhang Y, Zelinka MD, Pincus R, Boyle J, Gleckler PJ (2013) Are climate model simulations of clouds improving? An evaluation using the ISCCP simulator. J Geophys Res Atmos 118:13291342. https://doi.org/10.1002/jgrd.50141

Kramer M, Heinzeller D, Hartmann H, van den Berg W, Steeneveld GJ (2017) Numerical weather prediction in the grey zone using a global variable resolution mesh and scale-aware convection parameterisation using MPAS. Clim Dyn (in review)

Landelius T, Dahlgren P, Gollvik S, Jansson A, Olsson E (2016) A high-resolution regional reanalysis for Europe. Part 2: 2D analysis of surface temperature, precipitation and wind. Q J R Meteorol Soc 142(698):2132-2142. https://doi.org/10.1002/qj.2813

Lenderink G, van Meijgaard E (2008) Increase in hourly precipitation extremes beyond expectations from temperature changes. Nat Geosci 1(8):511-514. https://doi.org/10.1038/ngeo262

Llasat MC, Llasat-Botija M, Petrucci O, Pasqua AA, Rosselló J, Vinet F, Boissier L (2013) Towards a database on societal impact of Mediterranean floods within the framework of the HYMEX project. Nat Hazards Earth Syst Sci 13(5):1337-1350

Maraun D, Shepherd TG, Widmann M, Zappa G, Walton D, Gutiérrez JM, Hagemann S, Richter I, Soares PM, Hall A, Mearns LO (2017) Towards process-informed bias correction of climate change simulations. Nat Clim Change 7(11):764-773

Martinet M, Nuissier O, Duffourg F, Ducrocq V, Ricard D (2017) Finescale numerical analysis of the sensitivity of the hymex iop $16 \mathrm{a}$ heavy precipitating event to the turbulent mixing length parameterization. Q J R Meteorol Soc. https://doi.org/10.1002/qj.3167

Mass CF, Ovens D, Westrick K, Colle BA (2002) Does increasing horizontal resolution produce more skillful forecasts? Bull Am Meteor Soc 83(3):407-430

Meredith EP, Semenov VA, Maraun D, Park W, Chernokulsky AV (2015) Crucial role of Black Sea warming in amplifying the 2012 Krymsk precipitation extreme. Nat Geosci 8:615-619. https://doi. org/10.1038/NGEO2483

Milovac J, Warrach-Sagi K, Behrendt A, Späth F, Ingwersen J, Wulfmeyer V (2016) Investigation of PBL schemes combining the WRF model simulations with scanning water vapor differential absorption lidar measurements. J Geophys Res Atmos 121:624649. https://doi.org/10.1002/2015JD023927

Pontoppidan M, Reuder J, Mayer S, Kolstad EW (2017) Downscaling an intense precipitation event in complex terrain: the importance of high grid resolution. Tellus A: Dyn Meteorol Oceanogr 69(1): 1271561

Prein A, Gobiet A, Suklitsch M, Truhetz H, Awan N, Keuler K, Georgievski G (2013a) Added value of convection permitting seasonal simulations. Clim Dyn 41(9-10):2655-2677

Prein AF, Holland GJ, Rasmussen RM, Done J, Ikeda K, Clark MP, Liu $\mathrm{CH}$ (2013b) Importance of regional climate model grid spacing for the simulation of heavy precipitation in the Colorado headwaters. J Clim 26(13):4848-4857

Prein AF, Langhans W, Fosser G, Ferrone A, Ban N, Goergen K, Keller M, Tölle M, Gutjahr O, Feser F et al (2015) A review on regional convection-permitting climate modeling: Demonstrations, prospects, and challenges. Rev Geophys 53:323-361

Prein AF, Liu C, Ikeda K, Trier SB, Rasmussen RM, Holland GJ, Clark MP (2017) Increased rainfall volume from future convective storms in the US. Nat Clim Change 7(12):880

Rasmussen R et al (2014) Climate change impacts on the water balance of the Colorado headwaters: High-resolution regional climate model simulations. J Hydrometeorol 15:1091-1116. https://doi. org/10.1175/JHM-D-13-0118.1

Ribes A, Soulivanh T, Vautard R, Dubuisson B, Somot S, Colin J, Planton S, Soubeyroux J-M (2018) Observed increase in extreme daily rainfall in the French Mediterranean. Clim Dyn. https://doi.org/10.1007/s00382-018-4179-2
Scherrer SC, Begert M, Croci-Maspoli M, Appenzeller C (2016) Long series of Swiss seasonal precipitation: regionalization, trends and influence of large-scale flow. Int J Climatol. https:// doi.org/10.1002/joc.4584 (in press)

Schwitalla T, Bauer H-S, Wulfmeyer V, Warrach-Sagi K (2017) Continuous high-resolution midlatitude-belt simulations for JulyAugust 2013 with WRF. Geosci Model Dev 10:2031-2055. https://doi.org/10.5194/gmd-10-2031-2017

Shepherd TG (2014) Atmospheric circulation as a source of uncertainty in climate change projections. Nat Geosci 7(10):703-708

Sherwood SC, Bony S, Dufresne JL (2014) Spread in model climate sensitivity traced to atmospheric convective mixing. Nature 505(7481):37-42

Siebesma AP, Soares P, Teixeira J (2007) A combined eddy diffusivity mass-flux approach for the convective boundary layer. J Atmos Sci 64:1230-1248

Soares PMM, Miranda PMA, Siebesma AP, Teixeira J (2004) An eddydiffusivity/mass-flux parametrization for dry and shallow cumulus convection. Q J R Meteorol Soc 130:3365-3384

Stevens B, Bony S (2013) What are climate models missing? Science 340(6136):1053-1054

Stucki P, Brönnimann S, Martius O, Welker C, Rickli R, Dierer S, Bresch DN, Compo GP, Sardeshmukh PD (2015) Dynamical downscaling and loss modeling for the reconstruction of historical weather extremes and their impacts: a severe Foehn storm in 1925. Bull Am Meteorol Soc 96(8):1233-1241

Tabary P, Dupuy P, Lhenaff G, Gueguen C, Moulin L, Laurantin O, Merlier C, Soubeyroux JM (2012) A 10-year (1997-2006) reanalysis of quantitative precipitation estimation over France: methodology and first results. IAHS-AISH 351:255-260

Tebaldi C, Knutti R (2007) The use of the multi-model ensemble in probabilistic climate projections. Philos Trans R Soc Lond A Math Phys Eng Sci 365(1857):2053-2075

Teixeira J et al (2008) Parameterization of the atmospheric boundary layer. Bull Am Meteorol Soc 89(4):453-458. https://doi. org/10.1175/BAMS-89-4-453

Teixeira J, Cardoso S, Bonazzola M, Cole J, Del Genio A, DeMott C, Franklin C, Hannay C, Jakob C, Jiao Y, Karlsson J, Kitagawa H, Köhler M, Kuwano-Yoshida A, LeDrian C, Li J, Lock A, Miller MJ, Marquet P, Martins J, Mechoso CR, van Meijgaard E, Meinke I, Miranda PMA, Mironov D, Neggers R, Pan HL, Randall DA, Rasch PJ, Rockel B, Rossow WB, Ritter B, Siebesma AP, Soares PMM, Turk FJ, Vaillancourt PA, Von Engeln A, Zhao M (2011) Tropical and sub-tropical cloud transitions in weather and climate prediction models: The GCSS/ WGNE Pacific Cross-section Intercomparison (GPCI). J Clim 24:5223-5256. https://doi.org/10.1175/2011JCLI3672.1

Tölle MH, Gutjahr O, Thiele J, Busch G (2014) Increasing bioenergy production on arable land: does the regional and local climate respond? Germany as a case study. J Geophys Res Atmos 119(6):2711-2724. https://doi.org/10.1002/2013JD020877

Tölle MH, Schefczyk L, Gutjahr O (2017) Scale dependency of regional climate modeling of current and future climate extremes in Germany. Theor Appl Climatol. https://doi. org/10.1007/s00704-017-2303-6

Vautard R, van Oldenborgh G-J, Thao S, Dubuisson B, Lenderink G, Ribes A, Planton S, Soubeyroux J-M, Yiou P (2015) Extreme fall precipitations in the Cévennes mountains. On "explaining extreme events of 2014 from a climate perspective". Bull Am Meteorol Soc Suppl 96:S56-S60

Warrach-Sagi K, Schwitalla T, Wulfmeyer V, Bauer H-S (2013) Evaluation of a climate simulation in Europe based on the WRF-NOAH model system: precipitation in Germany. Clim Dyn 41:755-774

Webb MJ, Lock AP, Bretherton CS, Bony S, Cole JNS, Idelkadi A, Kang SM, Koshiro T, Kawai H, Ogura T, Roehrig R, Shin Y, 
Mauritsen T, Sherwood SC, Vial J, Watanabe M, Woelfle MD, Zhao M (2015) The impact of parametrized convection on cloud feedback. Philos Trans R Soc A. https://doi.org/10.1098/ rsta.2014.0414

Weisman ML, Skamarock W, Klemp JB (1997) The resolution dependence of explicitly modeled convective systems. Mon Weather Rev 125:527-548, https://doi.org/10.1175/15200493(1997)125\%3C0527:TRDOEM\%3E2.0.CO;2

Westra S, Fowler HJ, Evans JP, Alexander LV, Berg P, Johnson F, Kendon EJ, Lenderink G, Roberts NM (2014) Future changes to the intensity and frequency of short-duration extreme rainfall. Rev Geophys 52:522-555. https://doi.org/10.1002/2014RG000464

Wu L (2009) Comparison of atmospheric infrared sounder temperature and relative humidity profiles with NASA African Monsoon multidisciplinary analyses (NAMMA) dropsonde observations. J Geophys Res 114:D19205. https://doi.org/10.1029/2009JD012083
Wüest M, Frei C, Altenhoff A, Hagen M, Litschi M, Schär C (2010) A gridded hourly precipitation dataset for Switzerland using raingauge analysis and radar-based disaggregation. Int J Climatol 30:1764-1775. https://doi.org/10.1002/joc.2025

Yano JI, Soares PMM, Köhler M, Deluca A (2015) The convective parameterization problem: breadth and depth. Bull Am Meteor Soc 96(8):ES127-ES130

Yano JI, Ziemiański MZ, Cullen M, Termonia P, Onvlee J, Bengtsson L, Carrassi A, Davy R, Deluca A, Gray SL, Homar V (2017) Scientific challenges of convective-scale numerical weather prediction. Bull Am Meteorol Soc 99(4):699-710. http://hdl.handl e.net/1854/LU-8554921

Zappa G, Shepherd TG (2017) Storylines of atmospheric circulation change for european regional climate impact assessment. Am Met Soc. https://doi.org/10.1175/JCLI-D-16-0807.1

\section{Affiliations}

\section{Erika Coppola ${ }^{1}$ - Stefan Sobolowski ${ }^{2} \cdot$ E. Pichelli ${ }^{1} \cdot$ F. Raffaele ${ }^{1} \cdot$ B. Ahrens ${ }^{3} \cdot$ I. Anders $^{4} \cdot$ N. Ban $^{5} \cdot$ S. Bastin $^{6}$. M. Belda $\cdot$ D. Belusic ${ }^{8} \cdot$ A. Caldas-Alvarez ${ }^{9}$ R. M. Cardoso ${ }^{10}$ - S. Davolio ${ }^{11} \cdot$ A. Dobler ${ }^{12} \cdot$ J. Fernandez $^{13} \cdot$ L. Fita $^{14}$. Q. Fumiere ${ }^{15} \cdot$ F. Giorgi ${ }^{1} \cdot$ K. Goergen ${ }^{16,17} \cdot$ I. Güttler ${ }^{18} \cdot$ T. Halenka $^{7} \cdot$ D. Heinzeller ${ }^{19,20} \cdot \emptyset$. Hodnebrog ${ }^{21} \cdot$ D. Jacob ${ }^{22}$. S. Kartsios ${ }^{23}$ - E. Katragkou ${ }^{23}$ - E. Kendon ${ }^{24}$ - S. Khodayar ${ }^{9}$ H. Kunstmann ${ }^{19,25} \cdot$ S. Knist ${ }^{17,26}$ - A. Lavín-Gullón ${ }^{27}$. P. Lind ${ }^{8} \cdot$ T. Lorenz ${ }^{2} \cdot$ D. Maraun ${ }^{28} \cdot$ L. Marelle ${ }^{21} \cdot$ E. van Meijgaard ${ }^{29}$. J. Milovac ${ }^{30} \cdot$ G. Myhre $^{21} \cdot$ H.-J. Panitz ${ }^{9}$.

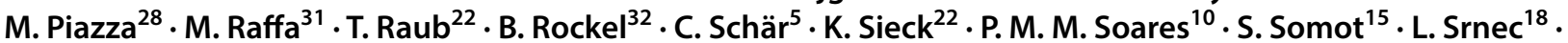

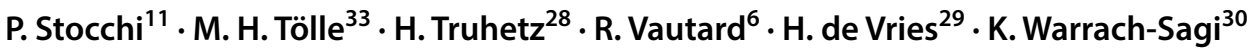

Erika Coppola coppolae@ictp.it

$\triangle$ Stefan Sobolowski stefan.sobolowski@uni.no

1 International Centre for Theoretical Physics (International Center for Theoretical Physics (ICTP)), Trieste, Italy

2 Uni Research, The Bjerknes Centre for Climate Research, Bergen, Norway

3 Goethe-Universitaet Frankfurt a.M. Frankfurt/Main, Frankfurt, Germany

4 ZAMG (Central Institute for Meteorology and Geodynamics), Vienna, Austria

5 Institute for Atmospheric and Climate Science, ETH Zürich, Zurich, Switzerland

6 Institut Pierre Simon Laplace (IPSL), LATMOS, UVSQ, UPMC, CNRS, Guyancourt, France

7 Department of Atmospheric Physics, Faculty of Mathematics and Physics, Charles University, Prague, Czech Republic

8 Swedish Meteorological and Hydrological Institute (SMHI), Norrköping, Sweden

9 Karlsruhe Institute of Technology, Institute of Meteorology and Climate Research-Troposphere Research, Karlsruhe, Germany

10 Instituto Dom Luiz, Faculdade de Ciências, Universidade de Lisboa, Lisbon, Portugal

11 Institute of Atmospheric Sciences and Climate, National Research Council of Italy, CNR-ISAC, Bologna, Italy
12 The Norwegian Meteorological Institute, Oslo, Norway

13 Meteorology Group, Department of Applied Mathematics and Computer Science, Universidad de Cantabria, Santander, Spain

14 Centro de Investigaciones del Mar y la Atmósfera (CIMA), CONICET-UBA, CNRS UMI-IFAECI, Buenos Aires, Argentina

15 CNRM (Centre National de Recherches Météorologiques), Université de Toulouse, Météo-France, CNRS, Toulouse, France

16 Institute of Bio-and Geosciences (Agrosphere, IBG-3), Research Centre Jülich, Jülich, Germany

17 Centre for High-Performance Scientific Computing in Terrestrial Systems, Geoverbund ABC/J, Jülich, Germany

18 Meteorological and Hydrological Service (DHMZ), Zagreb, Croatia

19 Institute of Meteorology and Climate Research (IMK-IFU), Karlsruhe Institute of Technology (KIT), Kreuzeckbahnstr. 19, 82467 Garmisch-Partenkirchen, Germany

20 Earth System Research Laboratory, National Oceanic and Atmospheric Administration, Boulder, CO, USA

21 Center for International Climate and Environmental Research-Oslo (CICERO), Oslo, Norway

22 Climate Service Center (CSC) Helmholtz-Zentrum Geesthacht Hamburg, Hamburg, Germany

23 Department of Meteorology and Climatology, School of Geology, Aristotle University of Thessaloniki, Greece, UK 
24 Met Office Hadley Centre, Exeter, UK

25 Institute of Geography, Augsburg University, Augsburg, Germany

26 Meteorological Institute, University of Bonn, Bonn, Germany

27 Meteorology Group, Instituto de Física de Cantabria (IFCA), CSIC-Univ. Cantabria, Santander, Spain

28 Wegener Center for Climate and Global Change (WEGC), University of Graz, Brandhofgasse 5, 8010 Graz, Austria

29 Royal Netherlands Meteorological Institute (KNMI), De Bilt, The Netherlands
30 Institute of Physics and Meteorology (IPM), University of Hohenheim, Stuttgart, Germany

31 Euro-Mediterranean Center on Climate Change (CMCC Foundation), Capua, Italy

32 Helmholtz-Zentrum Geesthacht, Geesthacht, Germany

33 Department of Geography, Climatology, Climate Dynamics and Climate Change, Justus-Liebig-University Giessen, Senckenbergstr. 1, 35390 Giessen, Germany 